\title{
UNCERTAINTY AND SENSITIVITY ANALYSIS IN PERFORMANCE ASSESSMENT FOR THE WASTE ISOLATION PILOT PLANT
}

\author{
J.C. Helton \\ Department of Mathematics \\ Arizona State University \\ Tempe, AZ 85287-1804
}

\begin{abstract}
O.STI

The Waste Isolation Pilot Plant (WIPP) is under development by the U.S. Department of Energy (DOE) for the geologic (deep underground) disposal of transuranic (TRU) waste. This development has been supported by a sequence of performance assessments (PAs) carried out by Sandia National Laboratories (SNL) to assess what is known about the WIPP and to provide guidance for future DOE research and development activities. Uncertainty and sensitivity analysis procedures based on Latin hypercube sampling and regression techniques play an important role in these PAs by providing an assessment of the uncertainty in important analysis outcomes and identifying the sources of this uncertainty. Performance assessments for the WIPP are conceptually and computationally interesting due to regulatory requirements to assess and display the effects of both stochastic (i.e., aleatory) and subjective (i.e., epistemic) uncertainty, where stochastic uncertainty arises from the possible disruptions that could occur over the $10,000 \mathrm{yr}$ regulatory period associated with the WIPP and subjective uncertainty arises from an inability to unambiguously characterize the many models and associated parameters required in a PA for the WIPP. The interplay between uncertainty analysis, sensitivity analysis, stochastic uncertainty and subjective uncertainty are discussed and illustrated in the context of a recent PA carried out by SNL to support an application by the DOE to the U.S. Environmental Protection Agency for the certification of the WIPP for the disposal of TRU waste.
\end{abstract}

RECEIVEL

DEC 231998

Keywords: Aleatory uncertainty, epistemic uncertainty, performance assessment, radioactive waste disposal, sensitivity analysis, stochastic uncertainty, subjective uncertainty, uncertainty analysis, Waste Isolation Pilot Plant. 


\section{DISCLAIMER}

This report was prepared as an account of work sponsored by an agency of the United States Government. Neither the United States Government nor any agency thereof, nor any of their employees, make any warranty, express or implied, or assumes any legal liability or responsibility for the accuracy, completeness, or usefulness of any information, apparatus, product, or process disclosed, or represents that its use would not infringe privately owned rights. Reference herein to any specific commercial product, process, or service by trade name, trademark, manufacturer, or otherwise does not necessarily constitute or imply its endorsement, recommendation, or favoring by the United States Government or any agency thereof. The views and opinions of authors expressed herein do not necessarily state or reflect those of the United States Government or any agency thereof. 


\section{DISCLAIMER}

\section{Portions of this document may be illegible in electronic image products. Images are produced from the best available original document.}




\section{INTRODUCTION}

The Waste Isolation Pilot Plant (WIPP) is under development by the U.S. Department of Energy (DOE) for the geologic (deep underground) disposal of transuranic waste (TRU) [1, 2]. The WIPP is located in southeastern New Mexico, with waste disposal planned to take place in excavated chambers (i.e., waste panels) in a salt formation approximately $2000 \mathrm{ft}$ below the land surface (Fig. 1).

An important part of the development process for the WIPP has been a series of uncertainty and sensitivity analyses carried out by Sandia National Laboratories (SNL) to assess the current state of knowledge with respect to the WIPP and to provide guidance for future model development and research activities [3-6], with these analyses having been extensively reported in the journal literature [7-12]. The most recent uncertainty and sensitivity analyses $[13,14]$ have been carried out in support of an application by the DOE to the U.S. Environmental Protection Agency (EPA) for the certification of the WIPP for the disposal of TRU waste (i.e., the compliance certification application or CCA) [15]. If certified, the WIPP will be the first facility in the United States to begin operations for the geologic disposal of radioactive waste.

Regulations promulgated by the EPA (i.e., 40 CFR 191, Subpart B $[16,17]$ ) determine the nature of the calculations performed by SNL to support the CCA and also the uncertainty and sensitivity analyses implemented as part of these calculations. The following is the central requirement of 40 CFR 191, Subpart B, and the primary determinant of the structure of the analysis (i.e., performance assessment or PA) carried out to support the CCA:

\section{$\S 191.13$ Containment requirements.}

(a) Disposal systems for spent nuclear fuel or high-level or transuranic radioactive wastes shall be designed to provide a reasonable expectation, based upon performance assessments, that cumulative releases of radionuclides to the accessible environment for 10,000 years after disposal from all significant processes and events that may affect the disposal system shall: (1) Have a likelihood of less than one chance in 10 of exceeding the quantities calculated according to Table 1 (Appendix A); and (2) Have a likelihood of less than one chance in 1,000 of exceeding ten times the quantities calculated according to Table 1 (Appendix A).

(b) Performance assessments need not provide complete assurance that the requirements of 191.13(a) will be met. Because of the long time period involved and the nature of the events and processes of interest, there will inevitably be substantial uncertainties in projecting disposal system performance. Proof of the future performance of a disposal system is not to be had in the ordinary sense of the word in situations that deal with much shorter time frames. Instead, what is required is a reasonable expectation, on the basis of the record before the implementing agency, that compliance with 191.13(a) will be achieved.

Containment Requirement 191.13(a) refers to "quantities calculated according to Table 1 (Appendix A)," which means a normalized radionuclide release to the accessible environment based on the type of waste being disposed of, the initial waste inventory, and the release that takes place (App. A, [16]). Table 1 (App. A) of [16] specifies allowable releases (i.e., release limits) for individual radionuclides. The WIPP is intended for TRU waste, which is defined to be "waste containing more than 100 nanocuries of alpha-emitting transuranic isotopes, with half-lives greater than twenty years, per gram of waste" (p. 38084, [16]). Specifically, the normalized release $R$ for transuranic waste is defined by

$$
R=\sum_{i}\left(Q_{i} / L_{i}\right)\left(1 \times 10^{6} \mathrm{Ci} / C\right)
$$

where $Q_{i}$ is the cumulative release of radionuclide $i$ to the accessible environment during the 10,000-yr period following closure of the repository $(\mathrm{Ci}), L_{i}$ is the release limit $(\mathrm{Ci})$ for radionuclide $i$ (Table 1, App. A, [16]) and $C$ is the amount of TRU waste emplaced in the repository (Ci). For the 1996 WIPP PA (i.e., the PA carried out in support of the $\mathrm{CCA}$ ), $C=3.44 \times 10^{6} \mathrm{Ci}$. 
To help clarify the intent of 40 CFR 191, the EPA also published 40 CFR 194 [18]. There, the following elaboration on the intent of 40 CFR 191.13 appears (pp. 5242-5243, [1 1 ]):

$\$ 194.34$ Results of performance assessments.

(a) The results of performance assessments shall be assembled into "complementary, cumulative distribution functions" (CCDFs) that represent the probability of exceeding various levels of cumulative release caused by all significant processes and events. (b) Probability distributions for uncertain disposal system parameter values used in performance assessments shall be developed and documented in any compliance application. (c) Computational techniques, which draw random samples from across the entire range of the probability distributions developed pursuant to paragraph (b) of this section, shall be used in generating CCDFs and shall be documented in any compliance application. (d) The number of CCDFs generated shall be large enough such that, at cumulative releases of 1 and 10, the maximum CCDF generated exceeds the 99th percentile of the population of CCDFs with at least a 0.95 probability. (e) Any compliance application shall display the full range of CCDFs generated. (f) Any compliance application shall provide information which demonstrates that there is at least a 95 percent level of statistical confidence that the mean of the population of CCDFs meets the containment requirements of $\S 191.13$ of this chapter.

An interesting feature of analyses to assess compliance with 191.13(a) and (b) is the requirement to incorporate two distinct treatments of uncertainty [19-21]. First, there is the uncertainty that leads to the CCDF specified in 191.13(a). This uncertainty results from an assumed randomness in what will occur at the WIPP site over the next $10,000 \mathrm{yr}$. Numerous designations for such uncertainty have been used in the literature, including stochastic, aleatory, variability, irreducible and type A. Second, there is the uncertainty characterized by the distributions called for in 194.34(b). This uncertainty results from a lack of knowledge about models and parameter values required in the construction of the CCDF specified in 191.13(a) and leads to the distribution of CCDFs called for in 194.34(e). Numerous designations for this characterization of uncertainty have also been used, including subjective, epistemic, state of knowledge, reducible and type B. In this presentation, stochastic and subjective will be used as the designations for these two types of uncertainty.

The terms uncertainty analysis and sensitivity analysis as used in analyses for the WIPP refer to assessments of the effects of subjective uncertainty. Specifically, uncertainty analysis designates an investigation of the uncertainty in model predictions that results from uncertainty in model inputs, and sensitivity analysis designates an investigation to determine the effects of individual variables on model predictions. Stochastic uncertainty enters into uncertainty and sensitivity analyses for the WIPP because the CCDF specified in 191.13(a), which derives from stochastic uncertainty, is the single most important result considered in such analyses.

\section{OVERVIEW OF PA FOR THE WIPP}

When viewed at a high level, three basic entities underlie the results required in 191.13 and 194.34 and ultimately determine the conceptual and computational structure of the 1996 WIPP PA: EN1, a probabilistic characterization of the likelihood of different futures occurring at the WIPP site over the next $10,000 \mathrm{yr} ; \mathrm{EN} 2$, a procedure for estimating the radionuclide releases to the accessible environment associated with each of the possible futures that could occur at the WIPP site over the next $10,000 \mathrm{yr}$; and EN3, a probabilistic characterization of the uncertainty in the parameters used in the definitions of EN1 and EN2. Together, EN1 and EN2 give rise to the CCDF specified in 191.13(a) (Fig. 2), and EN3 corresponds to the distributions indicated in 194.34(b). In the context of PA for the WIPP, uncertainty and sensitivity analysis involves the determination of the effects of the uncertainty characterized by EN3 on results that derive from EN1 and EN2.

The entity ENI is the outcome of the scenario development process for the WIPP and provides a probabilistic characterization of the likelihood of different futures that could occur at the WIPP over the next 10,000 yr as specified in 191.13(a). When viewed formally, EN1 is defined by a probability space $\left(\delta_{s t}, \delta_{s t}, P_{s t}\right)$, with the sample space $S_{s t}$ given by 
$S_{s t}=\left\{\mathbf{x}_{s s}: \mathbf{x}_{s t}\right.$ is a possible $10,000 \mathrm{yr}$ sequence of occurrences at the WIPP $\}$.

The subscript st refers to stochastic uncertainty and is used because $\left(S_{s t}, b_{s p}, p_{s t}\right)$ is providing a probabilistic characterization of random occurrences that may take place in the future.

Guidance by the EPA [18] and an extensive review of possible disruptions at the WIPP led to drilling intrusions and potash mining being the only occurrences incorporated into the definition of $S_{s t}$. Specifically, the elements $\mathbf{x}_{s t}$ of $S_{s t}$ are vectors of the form

$$
\mathbf{x}_{s t}=[\underbrace{t_{1}, l_{1}, e_{1}, b_{1}, p_{1}, \mathbf{a}_{1}}_{1^{\text {st }} \text { intrusion }}, \underbrace{t_{2}, l_{2}, e_{2}, b_{2}, p_{2}, \mathbf{a}_{2}}_{2^{\text {nd }} \text { intrusion }}, \ldots, \underbrace{t_{n}, l_{n}, e_{n}, b_{n}, p_{n}, \mathbf{a}_{n}}_{n^{\text {th }} \text { intrusion }}, t_{\min }]
$$

in the 1996 WIPP PA, where $n$ is the number of drilling intrusions, $t_{i}$ is the time $(\mathrm{yr})$ of the $i^{\text {th }}$ intrusion, $l_{i}$ designates the location of the $i^{\text {th }}$ intrusion, $e_{i}$ designates the penetration of an excavated or nonexcavated area by the $i^{\text {th }}$ intrusion, $b_{i}$ designates whether or not the $i^{\text {th }}$ intrusion penetrates pressurized brine in the Castile Formation, $p_{i}$ designates the plugging procedure used with the $i^{\text {th }}$ intrusion (i.e., continuous plug, two discrete plugs, three discrete plugs), $a_{i}$ designates the type of waste penetrated by the $i^{\text {th }}$ intrusion (i.e., no waste, contact-handled (CH) waste, remote-handled (RH) waste), and $t_{\min }$ is the time $(\mathrm{yr})$ at which potash mining occurs. A full characterization of $\left(\mathcal{S}_{s t}\right.$, $\delta_{s t}, p_{s t}$ ) then results from the definition of a probability distribution for each element of $\mathbf{x}_{s t}$ (Chapt. 3, [13]).

The entity EN2 is the outcome of the model development process for the WIPP and provides a way to estimate radionuclide releases to the accessible environment (i.e., values for $Q_{i}$, and hence $R$, in Eq. (1)) for the different futures (i.e., elements $x_{s t}$ of $S_{s t}$ ) that could occur at the WIPP. Estimation of environmental releases corresponds to evaluation of the function $f$ in Fig. 2. Release mechanisms associated with $f$ include direct removal to the surface at the time of a drilling intrusion (i.e., cuttings, spallings, direct brine flow) and release subsequent to a drilling intrusion due to brine flow up a borehole with a degraded plug (i.e., groundwater transport). The primary computational models in the 1996 WIPP PA are illustrated in Fig. 3 and described in more detail in Table 1. Most of these models involve the numerical solution of partial differential equations used to represent material deformation, fluid flow or radionuclide transport. It is the models in Fig. 3 that actually define the function $f$ in Fig. 2 .

As indicated in Fig. 1, the CCDF specified in 191.13(a) can be formally defined by an integral of $f$ over $S_{s r}$ In practice, this CCDF is never obtained by direct evaluation of an integral due to the complexity of $f$ and $\delta_{s r}$. Rather, an approximation procedure based on importance sampling [33] or Monte Carlo (random) sampling [34] is used. The 1996 WIPP PA uses a Monte Carlo procedure. Specifically, elements $\mathbf{x}_{s t, i}, i=1,2, \ldots, n S$, are randomly sampled from $S_{s t}$ in consistency with the definition of $\left(\mathcal{S}_{s t}, \mathcal{S}_{s t}, p_{s t}\right)$ where $n S$ is the sample size. Then, the integral in Fig. 2, and hence the associated CCDF, is approximated by

$$
\operatorname{prob}(\operatorname{Rel}>R)=\int_{S_{s t}} \delta_{R}\left[f\left(\mathbf{x}_{s t}\right)\right] d_{s t}\left(\mathbf{x}_{s t}\right) d V_{s t} \doteq \sum_{i=1}^{n S} \delta_{R}\left[f\left(\mathbf{x}_{s t, i}\right)\right] / n S,
$$

where $\delta_{R}\left[f\left(x_{s t}\right)\right]=1$ if $f\left(x_{s t}\right)>R$ and 0 if $f\left(x_{s t}\right) \leq R$. The models in Fig. 3 are too computationally intensive to permit their evaluation for every element $x_{s t, i}$ of $S_{s t}$ in Eq. (5). Due to this constraint, the models in Fig. 3 are evaluated for representative elements of $\delta_{s t}$ and then the results of these evaluations are used in conjunction with various interpolation and algebraic procedures to construct values of $f$ for the large number of $\mathbf{x}_{s t, i}$ in Eq. (5) (Chapts. 9 - 13, [13]). 
The entity EN3 is the outcome of the data development effort for the WIPP and provides a probabilistic characterization of the uncertainty in the parameters that underlie the WIPP PA. When viewed formally, EN3 is defined by a probability space $\left(\delta_{s u}, \delta_{s u}, p_{s u}\right)$, with the sample space $\delta_{s u}$ given by

$$
S_{s u}=\left\{\mathbf{X}_{s u}: \mathbf{X}_{s u} \text { is possibly the correct vector of parameter values to use in the WIPP PA }\right\} \text {. }
$$

The subscript $s u$ refers to subjective uncertainty and is used because $\left(\delta_{s u}, \mathscr{\delta}_{s u}, p_{s u}\right)$ is providing a probabilistic characterization of where the appropriate inputs to use in the WIPP PA are believed to be located.

In practice, $\mathbf{x}_{s u}$ is a vector of the form

$$
x_{s u}=\left[x_{1}, x_{2}, \ldots, x_{n v}\right]
$$

where $n V$ is the number of uncertain variables under consideration, and $\left(\mathcal{S}_{s u}, b_{s u}, p_{s u}\right)$ is obtained by specifying a distribution

$$
D_{j}, j=1,2, \ldots, n V
$$

for each element $x_{j}$ of $\mathbf{X}_{s u}$. The preceding distributions correspond to the distributions in 194.34(b). In concept, some elements of $\mathbf{x}_{s u}$ can affect the definition of $\left(S_{s t}, \delta_{s t}, p_{s t}\right)$ (e.g., the rate constant $\lambda_{d}$ used to define a Poisson process that characterizes the distribution of drilling intrusion times) and other elements can relate to the models in Fig. 3 that determine the function $f$ in Fig. 2 and Eq. (5) (e.g., radionuclide solubilities in Castile brine or fracture spacing in the Culebra Dolomite). However, all elements of $\mathbf{X}_{s u}$ in the 1996 WIPP PA relate to the models in Fig. 3 (Table 2).

The role of uncertainty analysis in PA for the WIPP is to determine the uncertainty in the predictions of the individual models in Fig. 3 and also the uncertainty in the location of the CCDF in Fig. 2 that results from the uncertainty characterized by $\left(\delta_{s u}, \delta_{s u}, p_{s u}\right)$. Similarly, the role of sensitivity analysis is to determine the contribution of the individual variables contained in $x_{s u}$ to this uncertainty.

\section{APPROACH TO UNCERTAINTÝ AND SENSITIVITY ANALYSIS}

The WIPP PA uses an approach to uncertainty and sensitivity analysis based on Monte Carlo procedures [35]. Specifically, a sample

$$
\mathbf{x}_{s u, k}=\left[x_{1 k}, x_{2 k}, \ldots, x_{n V, k}\right], k=1,2, \ldots, n K,
$$

is generated from $S_{s u}$ in consistency with the definition of $\left(\mathcal{S}_{s u}, \delta_{s u}, p_{s u}\right)$, where $n K$ is the sample size. Both the models in Fig. 3 and the CCDF in Fig. 2 are evaluated for the individual elements $x_{s u, k}$ of this sample.

The indicated model and CCDF evaluations for the sample elements $x_{s u, k}$ in Eq. (9) create a mapping from analysis input to analysis results. When an appropriate probabilistic procedure has been used to select the sample elements $\mathbf{x}_{s u, k}$, distributions can be constructed for individual model results and also for the CCDF specified in 191.13(a). Given that $\left(\mathcal{S}_{s u}, b_{s u}, p_{s u}\right)$ is providing a characterization of the subjective, or state of knowledge, uncertainty in the inputs to the analysis, the resultant distributions are providing a characterization for the corresponding uncertainty in the results of the analysis. Further, the pairing

$$
\left[\mathbf{x}_{s u, k}, \mathbf{g}\left(\mathbf{x}_{s u, k}\right)\right], k=1,2, \ldots, n K,
$$


of sample elements $\mathbf{x}_{s u . k}$ and analysis results of interest $\mathbf{g}\left(\mathbf{x}_{s u . k}\right)$ creates a mapping from analysis input to analysis results that can be explored with various sensitivity analysis procedures such as examination of scatterplots, stepwise regression analysis and partial correlation analysis [35].

As already indicated, the 1996 WIPP PA uses random sampling from $\left(\mathcal{S}_{s s}, \mathcal{\delta}_{s t}, p_{s t}\right)$ in the generation of the CCDF specified in 191.13(a). The use of random sampling is possible because a relatively small number of mechanistic results are used in the construction of the releases represented by $f\left(x_{s t, i}\right)$ in Eq. (5). Howevcr, the samples $x_{s u, k}$ in Eq. (9) are used directly as input to these mechanistic models; further, a complete CCDF construction is carried out for each $\mathbf{x}_{s u, k}$. Thus, it is important to use an efficient sampling technique in the generation of the $x_{s u . k}$. As a result, Latin hypercube sampling [36] was selected for use because of its efficient stratification properties and the observed stability of results obtained with relatively small sample sizes in past analyses that involved a separation of stochastic and subjective uncertainty $[37,38]$.

Latin hypercube sampling operates in the following manner to generate a sample of size $n L H S$ from $n V$ variables. The range of each variable (i.e., the $x_{j}$ in Eq. (7)) is divided into $n L H S$ intervals of equal probability and one value is selected at random from each interval. The $n L H S$ values thus obtained for $x_{1}$ are paired at random with the $n L H S$ values obtained for $x_{2}$. These $n L H S$ pairs are combined in a random manner with the $n L H S$ values of $x_{3}$ to form $n L H S$ triples. This process is continued until a set of $n L H S n V$-tuples is formed. These $n V$-tuples are of the form

$$
x_{i}=\left[x_{1 i}, x_{2 i} \ldots, x_{n V, i}\right], i=1, \ldots, n L H S
$$

and constitute the Latin hypercube sample (LHS). The individual $x_{j}$ must be independent for the preceding construction procedure to work; however, a method for generating LHSs from correlated variables has been developed by Iman and Conover $[39,40]$.

An LHS from two variables is illustrated in Fig. 4. As examination of this figure shows, Latin hypercube sampling results in a dense stratification across the range of each variable (i.e., there is one value from each equal probability interval), which is consistent with the requirement in $194.34(\mathrm{c})$ for sampling across the entire range of each variable.

Given that Latin hypercube sampling is to be used, the confidence intervals required in $194.34(f)$ can be obtained with a replicated sampling technique proposed by R.L. Iman [41]. In this technique, the LHS indicated in Eq. (11) is repeatedly generated with different random seeds. These samples lead to a sequence $\bar{P}_{r}(R), r=1,2, \ldots$, $n R$, of estimated mean exceedance probabilities, where $\bar{P}_{r}(R)$ defines the mean CCDF obtained for sample $r$ (i.e., $\bar{P}_{r}(R)$ is the mean probability that a normalized release of size $R$ will be exceeded, with this mean taken over the $n L H S$ exceedance probabilities for $R$ obtained from the $r^{\text {th }}$ replicated sample) and $n R$ is the number of independent LHSs generated with different random seeds. Then,

$$
\bar{P}(R)=\sum_{r=1}^{n R} \bar{P}_{r}(R) / n R
$$

and

$$
S E(R)=\left\{\sum_{r=1}^{n R}\left[\bar{P}_{r}(R)-\bar{P}(R)\right]^{2} / n R(n R-1)\right\}^{1 / 2}
$$

provide an additional estimate of the mean CCDF and an estimate of the standard error associated with the mean exceedance probabilities. The $t$-distribution with $n R-1$ degrees of freedom can be used to place confidence intervals 
around the mean exceedance probabilities for individual $R$ values (i.e., around $\bar{P}(R)$ ). Specifically, the $1-\alpha$ confidence interval is given by $\bar{P}(R) \pm t_{1-\alpha / 2} S E(R)$, where $t_{1-\alpha / 2}$ is the $1-\alpha / 2$ quantile of the $t$-distribution with $n R-1$ degrees of freedom (e.g., $t_{1-\alpha / 2}=4.303$ for $\alpha=0.05$ and $n R=3$ ).

The requirement in 194.34(d) implies the use of a sample with at least 298 elements (i.e., $1-0.99^{n}>0.95$ yields $n=298$ ). Thus, to satisfy both $194.34(f)$ and $194.34(d)$, the 1996 WIPP PA used $n R=3$ replicated LHSs of size $n L H S=100$ each, with these replicated samples denoted by R1, R2 and R3. This produced a total of 300 observations, which is approximately the same as the sample size of 298 indicated above. Each sample was generated with the restricted pairing technique developed by Iman and Conover $[39,40]$ to induce specified rank correlations between correlated variables and also to assure that uncorrelated variables had correlations close to zero.

Once the indicated LHSs were generated, calculations were performed with the models in Fig. 2 for the individual sample elements (Table 3). The guiding principle in the selection of the calculations to be performed was to avoid the unnecessary proliferation of computationally demanding calculations by identifying situations where (1) a single computationally demanding calculation could be used to supply input to several less demanding calculations, (2) mathematical properties of the models could be used to extend the results of a single calculation to many different situations, or (3) a relatively inexpensive screening calculation could be used to determine if a more detailed, and hence more expensive, calculation was needed. As examples, (1) each BRAGFLO calculation, which involves the numerical solution of a system of nonlinear partial differential equations and is quite demanding computationally (i.e., 4 - 5 hrs of CPU time on a Digital VAX Alpha using VMS), was used to supply conditions that were used in a number of different calculations with the CUTTINGS_S, BRAGFLO_DBR, NUTS and PANEL models; (2) the linearity of the system of partial differential equations that underlies SECOTP2D made it possible to perform transport calculations for unit releases of individual radionuclides to the Culebra Dolomite and then use the outcome of these calculations to construct transport results for arbitrary time-dependent radionuclide releases into the Culebra; and (3) transport calculations with NUTS were initially performed with a nondecaying tracer and then calculations with radionuclides were only performed for those cases that had a potential to result in a radionuclide release from the repository.

\section{UNCERTAINTY AND SENSITIVITY ANALYSIS FOR INDIVIDUAL MODELS}

As indicated in Table 3, many distinct cases exist for which uncertainty and sensitivity analysis results can be obtained for individual models. For example, 6 cases exist for BRAGFLO, with calculations having been performed with the same 300 LHS elements for each case. In each of these cases, the uncertainty is due solely to subjective uncerainty as characterized by $\left(S_{s u}, \delta_{s u}, p_{s u}\right)$. In particular, the effects of stochastic uncertainty as characterized by $\left(S_{s t}, b_{s t} P_{s t}\right)$ do not enter into the analysis until the results of individual models are used in the construction of CCDFs. Example uncertainty and sensitivity analysis results for individual models follow; more detailed results are available in Helton et al. [13].

The BRAGFLO model (Fig. 3, Table 1) is used to represent two-phase (i.e., gas and brine) flow in the vicinity of the repository. An important result calculated by BRAGFLO is the pressure in a waste panel as a function of time (Fig. 5a), with this pressure influencing spallings and direct brine releases, which are releases directly to the surface at the time of a drilling intrusion, and also radionuclide transport away from the repository in anhydrite marker beds. The spread in the curves in Fig. $5 \mathrm{a}$ is due to the effects of imprecisely-known inputs to the analysis (i.e., subjective uncertainty). One way to identify the variables that are dominating the uncertainty is to calculate partial rank correlation coefficients (PRCCs) between pressures at individual times and the variables in the LHS (Fig. 5b), with WMICDFLG (pointer variable for microbial degradation of cellulose), WGRCOR (corrosion rate for steel under inundated conditions in the absence of $\mathrm{CO}_{2}$ ), WASTWICK (increase in brine saturation of waste due to capillary forces) and HALPOR (initial value for halite porosity) being identified as the dominant variables (see Table 2 for variable descriptions). The positive effects indicated for these variables result because increasing WMICDFLG increases gas generation by microbial processes, increasing WGRCOR increases the rate at which gas is generated by the corrosion of steel, and increasing WASTWICK and HALPOR increases the amount of brine available for consumption in the corrosion process. 
The analysis was performed with 3 replicated LHSs (i.e., R1, R2, R3) to provide a basis for testing the stability of results obtained by sampling from $\left(\delta_{s u}, \delta_{s u}, p_{s u}\right)$. For time-dependent results such as the pressure curves in Fig. $5 \mathrm{a}$, such tests can be based on the similarity of mean and percentile curves obtained from the individual replicates and constructed in the following manner. At each point on the abscissa in Fig. 5a, a vertical line is drawn through the $n L H S=100$ curves above this point. The points at which the indicated vertical line crosses the curves yields $n L H S$ pressures from which the mean and various percentiles (e.g., 10\%,50\%, 90\%) can be determined. The desired mean and percentile curves then result from connecting the mean and percentile values obtained for individual times. In concept, the determination of mean and percentile values can be viewed as an integration problem involving $\left(\delta_{s u}\right.$, $\left.\delta_{s u}, p_{s u}\right)$ [42]. The resultant mean and percentile curves were quite stable for both the pressure curves in Fig. 5a (Fig. 6) and other analysis outcomes. If desired, the procedures indicated in Eqs. (12) and (13) can be used to provide a formal characterization of the uncertainty associated with the estimates of the individual curves in Fig. 6.

The results in Fig. 5 are for undisturbed conditions. An important event in the 1996 WIPP PA is the occurrence of a drilling intrusion into the repository, which causes a major alteration of the pressure conditions (Fig. 7a). Although PRCCs and also stepwise regression analysis were successful in identifying the variables giving rise to the uncertainty in Fig. 5a, they performed very poorly for the pressure results in Fig. 7a. When this occurs, the examination of scatterplots is often an effective way to identify influential variables, with a strong but highly nonlinear relationship being identified between pressure after a drilling intrusion and $B H P R M$ (logarithm of borehole permeability) (Figure 7b). The complex pattern involving pressure and BHPRM results from the role that BHPRM plays in influencing two-phase flow in the borehole, with gas flowing up the borehole and brine typically flowing down the borehole.

The NUTS and PANEL models (Fig. 3, Table 1) are used to represent long-term radionuclide transport away from the repository due to flowing groundwater. The NUTS model was used for undisturbed (i.e.,. E0) conditions, single drilling intrusions that penetrate pressurized brine in the Castile Formation (i.e., El intrusions), and single drilling intrusions that do not penetrate pressurized brine in the Castile Formation (i.e., E2 intrusions). The PANEL model was used for the penetration of a waste panel by two or more drilling intrusions, of which at least one penetrates pressurized brine in the Castile Formation (i.e., an E2E1 intrusion). Most sample elements resulted in little or no radionuclide release being predicted by NUTS and PANEL due to failure of the repository to fill with brine, with the greatest number of releases occurring for the E2EI intrusions. A single example of uncertainty and sensitivity analysis results for long-term radionuclide release from the repository is given in Fig. 8 . The box plots in Fig. 8a provide a compact way to display the uncertainty in a number of variables in a single plot frame. The variable $B H P R M$ dominates radionuclide release, with no releases typically occurring for small values of $B H P R M$ due to a failure of the intruded waste panel to fill with brine (Fig. 8b).

The SECOFL2D and SECOTP2D models (Fig. 3, Table 1) are used to represent brine flow and radionuclide transport, respectively, in the Culebra Dolomite. In the 1996 WIPP PA, only one sample element had the potential for radionuclide transport from the repository to the accessible environment. However, no releases to the Culebra occurred for this sample element. Thus, no release to the accessible environment due to transport through the Culebra occurred in the calculations performed to support the 1996 WIPP PA. To provide perspective on the processes affecting radionuclide transport in the Culebra, an additional set of calculations was performed for replicate R1 for a release of $1 \mathrm{~kg}$ of U-234 at the repository at time $0 \mathrm{yr}$ and the transport of this release in the near vicinity of the repository (i.e., within a few 10's of meters) (Fig. 9), with U-234 selected for consideration because it is the least retarded (i.e., has the lowest $k_{d}$ values) of the radionuclides whose transport in the Culebra was modeled in the 1996 WIPP PA. The release was rapidly attenuated (Fig. 9a), with the dominant variables being CMATRDU (Culebra matrix retardation for uranium), CVEL (norm of fluid velocity vector calculated by SECOFL2D) and CFRCSP (Culebra fracture spacing) (Fig. 9b). Specifically, CMATRDU characterizes the effects of sorption in the rock matrix; CVEL characterizes fluid velocity in fractures in the vicinity of the release point for the U-234, and CFRCSP affects the amount of diffusion that takes place from fractures into the sumounding rock matrix. A transport distance of only $10 \mathrm{~m}$ is used in Fig. 9 because the amount of cumulative transport decreases rapidly as distance increases; indeed, most of the 100 cumulative transport curves in Fig. 9a lie close to or on the abscissa. 


\section{UNCERTAINTY AND SENSITIVITY ANALYSIS FOR CCDFS}

Although a number of different release pathways to the accessible environment were considered in the 1996 WIPP PA, only the direct release pathways (i.e., cuttings, spallings, direct brine release) produced nonzero releases. As a result, the function $f$ in Eq. (5) has the form

$$
f\left(\mathbf{x}_{s t}\right)=f_{C}\left(\mathbf{x}_{s s}\right)+f_{S P}\left[\mathbf{x}_{s t}, f_{B}\left(\mathbf{x}_{s t}\right)\right]+f_{D B R}\left\{\mathbf{x}_{s t}, f_{S P}\left[\mathbf{x}_{s t}, f_{B}\left(\mathbf{x}_{s t}\right)\right], f_{B}\left(\mathbf{x}_{s t}\right)\right\}
$$

where (i) $f_{C}\left(\mathbf{x}_{s t}\right)$ - cuttings release to accessible environment for $\mathbf{x}_{s t}$ calculated with CUTTINGS_S, (ii) $f_{B}\left(\mathbf{x}_{s t}\right)$ results calculated for $\mathbf{X}_{s t}$ with BRAGFLO (in practice, $f_{B}\left(\mathbf{x}_{s t}\right)$ is a vector containing a large amount of information), (iii) $f_{S P}\left[\mathbf{x}_{s t}, f_{B}\left(\mathbf{x}_{s t}\right)\right]$ - spallings release to accessible environment for $\mathbf{x}_{s t}$ calculated with the spallings model contained in CUTTINGS_S (this calculation requires BRAGFLO results (i.e., $f_{B}\left(\mathbf{x}_{s s}\right)$ ) as input), and (iv) $f_{D B R}\left\{\mathbf{x}_{s t}, f_{S P}\left[\mathbf{x}_{s t}, f_{B}\left(\mathbf{x}_{s t}\right)\right], f_{B}\left(\mathbf{x}_{s t}\right)\right\}$ direct brine release to accessible environment for $\mathbf{x}_{s t}$ calculated with a modified version of BRAGFLO designated BRAGFLO_DBR (this calculation requires spallings results obtained from CUTTINGS_S (i.e., $\left.f_{S P}\left[\mathbf{x}_{s r} f_{B}\left(\mathbf{x}_{s t}\right)\right]\right)$ and BRAGFLO results (i.e., $\left.f_{B}\left(\mathbf{x}_{s t}\right)\right)$ as input).

As indicated in Eq. (5), random sampling of $\mathbf{x}_{s t}$ from $\left(S_{s t}, \delta_{s t}, p_{s t}\right)$ can be used to construct the CCDF in Fig. 2. Further, $f_{C}, f_{S P}$ and $f_{D B R}$ can also be used to obtain the CCDFs for cuttings, spallings and direct brine releases, respectively. The evaluation of $f_{C}, f_{S P}$ and $f_{D B R}$, and hence the evaluation of $f$, also depends on the value of $x_{s u}$. As a result, Eq. (5) actually has the form

$$
\operatorname{prob}\left(R e l>R \mid \mathbf{x}_{s u}\right)=\int_{\delta_{s t}} \delta_{R}\left[f\left(\mathbf{x}_{s t}, \mathbf{x}_{s u}\right)\right] d_{s t}\left(\mathbf{x}_{s t} \mid \mathbf{x}_{s u}\right) d V_{s t} \doteq \sum_{i=1}^{n S} \delta_{R}\left[f\left(\mathbf{x}_{s t, i}, \mathbf{x}_{s u}\right)\right] / n S,
$$

although there is no dependence of $d_{s i}$ on $\mathbf{x}_{s u}$ in the 1996 WIPP PA (i.e., $d_{s i}\left(\mathbf{x}_{s t} \mid \mathbf{x}_{s u}\right)=d_{s t}\left(\mathbf{x}_{s t}\right)$ ). However, such dependence is possible and, indeed, was implemented in certain verification analyses associated with the 1996 WIPP PA carried out by SNL for the EPA [43].

The uncertainty associated with $x_{s u}$, and characterized by $\left(\mathcal{S}_{s u}, b_{s u}, p_{s u}\right)$, leads to a distribution of CCDFs for $f_{C}, f_{S P}, f_{D B R}$ and $f$. These distributions can be approximated by constructing CCDFs for each element $\mathbf{x}_{s u, k}$ in the three replicated LHSs, with the outcomes of this construction shown in Fig. 10 for replicate R1. Each CCDF in Fig. 10 is constructed from model results (i.e., evaluations of $f_{C}, f_{S P}, f_{D B R}$ ) associated with one LHS element in R1. The details of the procedures used to obtain values of $f\left(\mathbf{x}_{s t, i}, \mathbf{x}_{s u, k}\right)$ from the results indicated in Table 3 are described in [13].

The distributions of CCDFs in Fig. 10 are showing the effects of subjective uncertainty. As such, these distributions are providing a characterization of where the CCDF for each release mode is believed to be located given the information available for use in the 1996 WIPP PA. The locations of the CCDFs for the spallings release (Fig. 10b) and direct brine release (Fig. 10c) are more uncertain than the location of the CCDF for the cuttings release (Fig. 10a). However, as the cuttings release tends to be larger than the spallings and direct brine releases, the uncertainty in the total release (Fig. 10d) is dominated by the uncertainty in the cuttings release (i.e., the distribution of CCDFs for total release is similar to, but not identical to, the distribution of CCDFs for cuttings release).

As discussed in conjunction with Fig. 5, the distributions of CCDFs in Fig. 10 can be summarized with mean and percentile curves. As an example, the mean and percentile curves for the distribution of total release CCDFs (Fig. 10d) appears in Fig. 11. The proximity of the distribution of the CCDFs to the boundary line associated with 191.13(a) provides an indication of the confidence that the regulation will indeed be met. The 90th percentile curve, or some other percentile curve, helps provide a numerical indication of where the distribution of CCDFs is located relative to the boundary line. 
The mean and percentile curves associated with the three replicated samples R1, R2 and R3 can be used to obtain an indication of how stable the estimates of the CCDFs in Fig. 10 are. In particular, the three estimates of these curves for a particular release mode (i.e., one set of estimates for each replicate) can be plotted on the same plot frame. When the corresponding curves fall close together, an indication is given that the sample size in use (i.e., $n L H S=100$ in this analysis) is adequate. For the cuttings, spallings and total releases, the individual mean and percentile curves for the three replicates are so similar that they almost fall on top of each other. Slightly more variation across the replicates occurs for the direct brine release (Fig. 12). However, cven here the individual curves are actually quite close together, particularly given that approximately half the sample elements in each replicate have no direct releases and thus produce degenerate CCDFs (i.e., CCDFs for which there is a probability of 0 of exceeding a release of 0). Thus, the distributions of CCDFs in the 1996 WIPP are adequately estimated for comparison with the boundary line specified in 191.13(a) with an LHS of size 100 .

Sensitivity analysis can be used to identify the variables contained in $\mathbf{x}_{s u}$ that give rise to the distributions of CCDFs in Fig. 10. One way to do this is to reduce each CCDF to an expected value by the calculation

$$
E\left(f \mid \mathbf{x}_{s u, k}\right)=\int_{S_{s t}} f\left(\mathbf{x}_{s t}, \mathbf{x}_{s u, k}\right) d_{s t}\left(\mathbf{x}_{s t} \mid \mathbf{x}_{s u, k}\right) d V_{s t} \doteq \sum_{i=1}^{n S} f\left(\mathbf{x}_{s t, i}, \mathbf{x}_{s u, k}\right) / n S .
$$

Then, regression analysis can be used to determine how the elements of $\mathbf{x}_{s u}$ affect $E\left(f \mid \mathbf{x}_{s u}\right)$. The expected values for $f_{C}, f_{S P}$ and $f_{D B R}$ can also be defined and analyzed in a similar manner.

In regression-based sensitivity analyses, variable importance is indicated by the order in which variables enter the regression model, the changes in $R^{2}$ values that occur as variables enter the regression model, and the size of the standardized regression coefficients for the variables in the model [35]. Regression analyses were tried with both raw and rank-transformed [44] data, with rank-transformed data producing more informative results (i.e., regression models that identified more of the physically-relevant variables and had higher $R^{2}$ values than was the case for raw data). Thus, only results obtained with rank-transformed data will be discussed.

For the cuttings release CCDFs, the expected release was completely dominated by WTAUFAIL (shear strength of waste), with the corresponding rank regression model having an $R^{2}$ value of essentially 1.00 . More complex patterns occur for the spallings, direct brine and total release CCDFs (Table 4). The spallings release is sensitive to the pressure in the repository. The variables WMICDFLG, HALPOR, WGRCOR, HALPRM and ANHPRM appear in the regression model with positive regression coefficients because increasing their values tends to increase pressure in the repository and thus increase the spallings release. In particular, there is a threshold value of $8 \times 10^{6} \mathrm{~Pa}$ in the spallings model, with no spallings releases occurring when repository pressure is below this value. The variables $B H P R M$ and WPRTDIAM appear in the regression model with negative coefficients because increasing $B H P R M$ reduces pressure in the repository and increasing WPRTDIAM increases particle size and thus decreases particle mobility. More detail on the physics underlying these and other results is available in [13]. Overall, the regression model is reasonably effective in accounting for the observed uncertainty, with an $R^{2}$ value of 0.77 .

The analysis for the direct brine release is less effective, with an $R^{2}$ value of only 0.50 (Table 4 ). When regression analyses have low $R^{2}$ values, the examination of scatterplots is often an effective way to gain insights into the variables affecting the analysis outcome under consideration. In this example, many expected values are zero, with the nonzero values tending to be associated with small values for WRBRNSAT (waste residual brine saturation) and large values for HALPOR (Fig. 13).

For the total release CCDFs, the expected release is dominated by WMICDFLG and WTAUFAIL (Table 4), which are the dominant variables with respect to the spallings and cuttings releases, respectively. The remaining variables selected in the analysis affect the spallings release (i.e., compare the regression results in Table 4 for spallings release and total release), which is reasonable given that the cuttings release is completely dominated by WTAUFAIL and the direct brine release makes little contribution to the total release (Fig. 10). 
An alternative way to perform sensitivity analyses for distributions of CCDFs is by calculating regression coefficients or parial correlation coefficients for the exceedance probabilities associated with individual release values and then connecting these coefficients to form curves (Fig. 14). This is analogous to the analysis in Fig. 5 for time-dependent pressures except that exceedance probabilities rather than pressures are now the dependent variables. For the total release CCDFs (Fig. 10d), the two dominant variables identified in this manner are WMICDFLG and WTAUFAIL (Fig. 14), which is consistent with the regression results in Table 4.

\section{SUMMÁRY}

The importance of identifying, characterizing and displaying the uncertainty in the outcomes of analyses for complex systems is now widely recognized [45]. The 1996 WIPP PA provides an example of an analysis for such a system. In particular, this analysis involves explicit treatments for both stochastic (i.e., aleatory) and subjective (i.e., epistemic) uncertainty.

Stochastic uncertainty is described by a probability space $\left(\delta_{s l}, \delta_{s t}, p_{s l}\right)$ that characterizes future occurrences at the WIPP. An assessment of the effects of stochastic uncertainty requires the evaluation of an integral over $\mathcal{S}_{s l}$, with this integral being evaluated with Monte Carlo procedures based on simple random sampling in the 1996 WIPP PA. The individual CCDFs in Fig. 10 are examples of such evaluations.

Subjective uncertainty is described by a probability space $\left(\mathcal{S}_{s u}, b_{s u}, p_{s u}\right)$ that characterizes the uncertainty in models and associated parameters required in the calculation of consequences (e.g., radionuclide releases to the accessible environment) associated with different possible future occurrences at the WIPP, with the likelihood that these occurrences will actually take place characterized by $\left(\mathcal{S}_{s s}, \delta_{s t}, p_{s t}\right)$. An assessment of the effects of subjective uncertainty (i.e., a determination of the uncertainty in analysis outcomes that results from subjective uncertainty) requires the evaluation of an integral over $\mathcal{S}_{s u}$, with this integral being evaluated with Monte Carlo procedures based on Latin hypercube sampling in the 1996 WIPP PA. For example, the individual curves in Fig. 5a are associated with individual sample elements in an LHS, and the mean and percentile results in Fig. 6 can be expressed formally as integrals involving $\left(\delta_{s u}, \delta_{s u}, p_{s u}\right)$. More generally, a combined assessment of the effects of stochastic and subjective uncertainty requires the evaluation of a double integral over $S_{s t}$ and $S_{s u}[21,42]$, with the mean and percentile curves in Fig. 11 arising from such evaluations.

Uncertainty analysis results are provided in the 1996 WIPP PA by the generation of an LHS (actually, 3 replicated LHSs) from $S_{s u}$ and the propagation of this sample through the analysis. This procedure also provides the basis for sensitivity analysis by providing a mapping between analysis inputs and analysis results as indicated in Eq. (10). Once generated, this mapping can be explored with procedures based on examination of scatterplots, regression analysis and correlation analysis (Figs. 5a, 7b, 8b, 9b, 13, 14; Table 4). In the presence of nonlinear but monotonic relationships, the use of the rank transformation [44] often improves results obtained with regression analysis and correlation analysis. In the presence of more complex patterns, other procedures for identifying deviations from randomness are often effective [46]. In PAs for the WIPP and other complex systems, sensitivity analysis plays an important role by both identifying important variables requiring additional study and providing a powerful tool for model verification (i.e., sensitivity analysis has the capability to identify errors that could be easily overlooked in less extensive examinations of analysis results).

\section{ACKNOWLEDGMENTS}

Work performed for Sandia National Laboratories (SNL), which is a multiprogram laboratory operated by Sandia Corporation, a Lockheed Martin Company, for the United States Department of Energy under contract DE-AC04-94AL85000. Many individuals at SNL and its contractors contributed to the results in this presentation, including D.R. Anderson, K. Aragon, J.E. Bean, J.W. Berglund, R. Blaine, F.J. Davis, K. Economy, D. Galson, J.W. Garner, J.D. Johnson, H.-N. Jow, K.W. Larson, M.E. Lord, R.J. MacKinnon, M.G. Marietta, J. Miller, D.G. O'Brien, J.L. Ramsey, L.C. Sanchez, J.D. Schreiber, A. Shinta, L.N. Smith, D.M. Stoelzel, C. Stockman, P.N. 
Swift, M.S. Ticrney, P. Vaughn, M. Wallace, and M. Williamson. Revicw provided at SNL by M. Chavez, C. Crawford and M.J. Shortencarier. Editorial support provided by L. Harrison, T. Allen, and H. Olmstead of Tech Reps, Inc.

\section{REFERENCES}

1. USDOE (U.S. Department of Energy). 1980. Final Environmental Impact Statement, Waste Isolation Pilot Plant. DOE/EIS-0026. Washington, DC: U.S. Department of Energy.

2. USDOE (U.S. Department of Energy). 1990. Final Supplement: Environmental Impact Statement, Waste Isolation Pilot Plant. DOE/EIS-0026-FS. Washington, DC: U.S. Department of Energy, Office of Environmental Restoration and Waste Management.

3. WIPP PA (Performance Assessment) Division. 1991-1992. Preliminary Comparison with 40 CFR Part 191, Subpart B for the Waste Isolation Pilot Plant, December 1991. Volumes 1-4. SAND91-0893/1-4. Albuquerque, NM: Sandia National Laboratories.

4. WIPP PA (Performance Assessment) Department. 1992-1993. Preliminan' Performance Assessment for the Waste Isolation Pilot Plant, December 1992. Volumes 1-5. SAND92-0700/1-5. Albuquerque, NM: Sandia National Laboratories.

5. Helton, J.C., Garner, J.W., McCurley, R.D., and Rudeen, D.K. 1991. Sensitivity Analysis Techniques and Results for Performance Assessment at the Waste Isolation Pilot Plant. SAND90-7103. Albuquerque, NM: Sandia National Laboratories.

6. Helton, J.C., Bean, J.E., Butcher, B.M., Garner, J.W., Schreiber, J.D., Swift, P.N., and Vaughn, P. 1993. Uncertainty and Sensitivity Analyses for Gas and Brine Migration at the Waste Isolation Pilot Plant, May 1992. SAND92-2013. Albuquerque, NM: Sandia National Laboratories.

7. Helton, J.C., Garner, J.W., Marietta, M.G., Rechard, R.P., Rudeen, D.K., and Swift, P.N. 1993. "Uncertainty and Sensitivity Analysis Results Obtained in a Preliminary Performance Assessment for the Waste Isolation Pilot Plant." Nuclear Science and Engineering 114, 286-331.

8. Helton, J.C., Anderson, D.R., Baker, B.L., Bean, J.E., Berglund, J.W., Beyeler, W. Garner, J.W., Iuzzolino, H.J., Marietta, M.G., Rechard, R.P., Roache, P.J., Rudeen, D.K., Schreiber, J.D., Swift, P.N., Tierney, M.S., and Vaughn, P. 1995b. "Effect of Alternative Conçeptual Models in a Preliminary Performance Assessment for the Waste Isolation Pilot Plant." Nuclear Engineering and Design 154, 251-344.

9. Helton, J.C., Anderson, D.R., Baker, B.L., Bean, J.E., Berglund, J.W., Beyeler, W., Economy, K., Garner, J.W., Hora, S.C., Iuzzolino, H.J., Knupp, P., Marietta, M.G., Rath, J., Rechard, R.P., Roache, P.J., Rudeen, D.K., Salari, K., Schreiber, J.D., Swift, P.N., Tierney, M.S., and Vaughn, P. 1996. "Uncertainty and Sensitivity Analysis Results Obtained in the 1992 Performance Assessment for the Waste Isolation Pilot Plant." Reliability' Engineering and System Safety 51, 53-100.

10. Helton, J.C., Bean, J.E., Butcher, B.M., Garner, J.W., Schreiber, J.D., Swift, P.N., and Vaughn, P. 1996. "Uncertainty and Sensitivity Analysis for Gas and Brine Migration at the Waste Isolation Pilot Plant: Fully Consolidated Shaft." Nuclear Science and Engineering 122: 1-31.

11. Helton, J.C., Bean, J.E., Butcher, B.M., Garner, J.W., Schreiber, J.D., Swift, P.N., and Vaughn, P. 1996. "Uncertainty and Sensitivity Analysis for Gas and Brine Migration at the Waste Isolation Pilot Plant: Permeable Shaft with Panel Seals." Journal of Hazardous Materials 45: 107-139. 
12. Helton, J.C., Bean, J.E., Butcher, B.M., Garner, J.W., Schreiber, J.D., Swift, P.N., and Vaughn, P. 1997. "Uncertainty and Sensitivity Analysis for Gas and Brine Migration at the Waste Isolation Pilot Plant: Permeable Shaft without Panel Seals." Reliability Enginecring and System Safety (to appear).

13. Helton, J.C. et al. 1998. Uncertainty and Sensitivity Analysis Results Obtained in the 1996 Performance Assessment for the Waste Isolation Pilot Plant. SAND98-0365. Albuquerque, NM: Sandia National Laboratories. In preparation.

14. Helton, J.C., Johnson, J.D., Jow, H.-N., McCurley, R.D., and Rahal, L.J. 1998. "Stochastic and Subjective Uncertainty in the Assessment of Radiation Exposure at the Waste Isolation Pilot Plant." Human and Ecological Risk Assessment (to appear).

15. USDOE (U.S. Department of Energy). 1996. Title 40 CFR Part 19I Compliance Certification Application for the Waste Isolation Pilot Plant. DOE/CAO-1996-2184. Carlsbad, NM: U.S. Department of Energy, Carlsbad Area Office.

16. USEPA (U.S. Environmental Protection Agency). 1985. "Environmental Standards for the Management and Disposal of Spent Nuclear Fuel, High-Level and Transuranic Radioactive Wastes; Final Rule, 40 CFR Part 191." Federal Register 50, 38066-38089.

17. USEPA (U.S. Environmental Protection Agency). 1993. "Environmental Radiation Protection Standards for the Management and Disposal of Spent Nuclear Fuel, High-Level and Transuranic Radioactive Wastes; Final Rule, 40 CFR Part 191." Federal Register 58, 66398-66416.

18. USEPA (U.S. Environmental Protection Agency). 1996. " 40 CFR Part 194: Criteria for the Certification and Re-Certification of the Waste Isolation Pilot Plant's Compliance with the 40 CFR Part 191 Disposal Regulations; Final Rule." Federal Register 61, 5224-5245.

19. Helton, J.C. 1993. "Risk, Uncertainty in Risk, and the EPA Release Limits for Radioactive Waste Disposal." Nuclear Technology 101, 18-39.

20. Helton, J.C. 1994. "Treatment of Uncertainty in Performance Assessments for Complex Systems." Risk Analysis 14, 483-511.

21. Helton, J.C. 1997. "Uncertainty and Sensitivity Analysis in the Presence of Stochastic and Subjective Uncertainty." Journal of Statistical Computation and Simulation 57, 3-76.

22. Bean, J.E., Lord, M.E., McArthur, D.A., MacKinnon, R.J., Miller, J.D., and Schreiber, J.D. 1996. “Analysis Package for the Salado Flow Calculations (Task 1) of the Performance Assessment Analysis Supporting the Compliance Certification Application (CCA)." Analysis package. SWCF-A:1.2.07.4.1:PA:QA:CCA. Albuquerque, NM: Sandia National Laboratories. Sandia WIPP Central Files WPO \# 40514.

23. Stoelzel, D.M., and O'Brien, D.G. 1996. "Analysis Package for the BRAGFLO Direct Release Calculations (Task 4) of the Performance Assessment Calculations Supporting the Compliance Certification Application (CCA), AP-029, Brine Release Calculations." Analysis package. SWCF-A:1.2.07.4.1:PA:QA. Albuquerque, NM: Sandia National Laboratories. Sandia WIPP Central Files WPO \#40520.

24. Berglund, J.W. 1992. Mechanisms Governing the Direct Removal of Wastes from the Waste Isolation Pilot Plant Repository Caused by Exploratory Drilling. SAND92-7295. Albuquerque, NM: Sandia National Laboratories.

25. Berglund, J.W. 1996. "Analysis Package for the Cuttings and Spalling Calculations (Tasks 5 and 6) of the Performance Assessment Calculation Supporting the Compliance Certification Application (CCA), AP-015 and AP-016." Analysis package. SWCF-A:1.2.07.4.1:PA:CCA:QA. Albuquerque, NM: Sandia National Laboratories. Sandia Central Files WPO \# 40521. 
26. LaVenue, A.M., and RamaRao, B.S. 1992. A Modeling Approach To Address Spatial Variability Within the Culebra Dolomite Transmissivin Field. SAND92-7306. Albuquerque, NM: Sandia National Laboratories.

27. LaVenue, A.M. 1996. "Analysis of the Generation of Transmissivity Fields for the Culebra Dolomite Compliance Certification Application (CCA)." Analysis package. SWCF-A:1.2.07.4.1:PA:QA. Albuqucrque, NM: Sandia National Laboratories. Sandia WIPP Central Files WPO \#40517.

28. Stockman, C., Shinta, A., and Garner, J.W. 1996. "Analysis Package for the Salado Transport Calculations (Task 2) of the Performance Assessment Analysis Supporting the Compliance Certification Application (CCA), AP-023." Analysis package. SWCF-A:1.2.07.4.1:PA:QA:CCA. Albuquerque, NM: Sandia National Laboratories. Sandia WIPP Central Files WPO $\# 40515$.

29. Roache, P.J. 1993. "The SECO Suite of Codes for Site Performance Assessment." High Level Radioactive Waste Management, Proceedings of the Fourth Annual International Conference, Las Vegas, NV, April 26-30, 1993. La Grange Park, IL: American Nuclear Society. Vol. 2, pp. 1586-1594.

30. Ramsey, J., and Wallace, M.G. 1996. "Analysis Package for the Culebra Flow and Transport Calculations (Task 3) of the Performance Assessment Calculations Supporting the Compliance Certification Application (CCA), Analysis Plan 019." Analysis package. SWCF-A:WA:1.2.07.4.1:QA. Albuquerque, NM: Sandia National Laboratories. Sandia WIPP Central Files WPO \#40516.

31. Stone, C.M. 1997. SANTOS - A Two-Dimensional Finite Element Program for the Quasistatic, Large Deformation, Inelastic Response of Solids. SAND90-0543. Albuquerque, NM: Sandia National Laboratories.

32. Stone, C.M. 1997. Final Disposal Room Structural Response Calculations. SAND97-0795. Albuquerque, NM: Sandia National Laboratories.

33. Helton, J.C., and Iuzzolino, H.J. 1993. "Construction of Complementary Cumulative Distribution Functions for Comparison with the EPA Release Limits for Radioactive Waste Disposal." Reliability Engineering and System Safety 40, 277-293.

34. Helton, J.C., and Shiver, A.W. 1996. "A Monte Carlo Procedure for the Construction of Complementary Cumulative Distribution Functions for Comparison with the EPA Release Limits for Radioactive Waste Disposal." Risk Analysis 16, 43-55,

35. Helton, J.C. 1993. "Uncertainty and Sensitivity Analysis Techniques for Use in Performance Assessment for Radioactive Waste Disposal." Reliability Engineering and System Safety 42, 327-367.

36. McKay, M.D., Beckman, R.J., and Conover, W.J. 1979. "A Comparison of Three Methods for Selecting Values of Input Variables in the Analysis of Output from a Computer Code." Technometrics 21, 239-245.

37. Iman, R.L., and Helton, J.C. 1991. "The Repeatability of Uncertainty and Sensitivity Analyses for Complex Probabilistic Risk Assessments." Risk Analysis 11, 591-606.

38. Helton, J.C., Johnson, J.D., McKay, M.D., Shiver, A.W., and Sprung, J.L. 1995. "Robustness of an Uncertainty and Sensitivity Analysis of Early Exposure Results with the MACCS Reactor Accident Consequence Model." Reliability Engineering and System Safety 48, 129-148.

39. Iman, R.L., and Conover, W.J. 1982. "A Distribution-Free Approach to Inducing Rank Correlation Among Input Variables." Communications in Statistics: Simulation and Computation B11, 311-334.

40. Iman, R.L., and Davenport, J.M. 1982. "Rank Correlation Plots for Use with Correlated Input Variables," Communications in Statistics: Simulation and Computation B11: 335-360. 
41. Iman, R.L. 1982. "Statistical Methods for Including Uncertaintics Associaled with the Genlogic Isolation of Radioactive Waste Which Allow for a Comparison with Licensing Criteria." Proceedings of the Symposium on Uncertainties Associated with the Regulation of the Geologic Disposal of High Level Radioactive Waste, Gatlinburg, Tennessee, March 9-13, 1981. Ed. D.C. Kocher. NUREG/CP-0022, CONF-810372. Oak Ridge, TN: Oak Ridge National Laboratory. pp. 145-157.

42. Helton, J.C. 1996. "Probability, Conditional Probability and Complementary Cumulative Distribution Functions in Performance Assessment for Radioactive Waste Disposal." Reliability Engineering and Sysiem Safety 54, 145-163.

43. Summary of EPA-Mandated Performance Assessment Verification Test (Replicate 1) and Comparison with the Compliance Certification Application Calculations. 1997. Albuquerque, NM: Sandia National Laboratories. Sandia WIPP Central Files WPO \# 46674.

44. Iman, R.L., and Conover, W.J. 1979. "The Use of the Rank Transform in Regression." Technometrics 21, 499-509.

45. Helton, J.C., and Burmaster, D.E. 1996. "Guest Editorial: Treatment of Aleatory and Epistemic Uncertainty in Performance Assessments for Complex Systems." Reliability Engineering and System Safety 54, 91-94.

46. Kleijnen, J.P.C., and Helton, J.C. 1998. "Statistical Analyses of Scatterplots to Identify Important Factors in Large-Scale Simulations." In preparation. 
Figs.

Captions

1. Cross-sectional view of the WIPP (Fig. 1-9, Vol. 1 [3]; see Sect. 2.2, Vol. 2 [4] for detailed stratigraphy).

2. Boundary line and associated CCDF specified in 191.13(a).

3. Computer programs (models) used in 1996 WIPP PA.

4. Example of an LHS of size $n L H S=10$ from variables $U$ and $V$ with $U$ normal on $[-1,1]$ (mean $=0,0.01$ quantile $=-1,0.99$ quantile $=1)$ and $V$ triangular on $[0,4]($ mode $=1)$.

5. Uncertainty and sensitivity analysis results for pressure $(\mathrm{Pa})$ in waste panel under undisturbed (i.e., E0) conditions: (5a) time-dependent pressures for 100 LHS elements in replicate R1, and (5b) PRCCs obtained from analysis of all 300 LHS elements associated with replicates R1, R2 and R3.

6. Mean and percentile curves for three replicated LHSs for pressure in lower waste panel under undisturbed conditions.

7. Uncertainty and sensitivity analysis results for pressure (Pa) in waste panel after a drilling intrusion at 1000 yr that does not penetrate pressurized brine in the Castile Formation (i.e., an E2 intrusion): (7a) timedependent pressures for 100 LHS elements in replicate R1, and (7b) scatterplot for pressure at $10,000 \mathrm{yr}$ versus $B H P R M$ for 300 LHS elements in replicates $\mathrm{R} 1, \mathrm{R} 2$ and $\mathrm{R} 3$.

8. Uncertainty and sensitivity analysis results for an E2E1 intrusion with the E1 intrusion occurring at $1000 \mathrm{yr}$ : (8a) box plots for cumulative normalized release of individual radionuclides over $10,000 \mathrm{yr}$, and (8b) scatterplot for cumulative normalized release of Am-241 over 10,000 yr versus BHPRM.

9. Uncertainty and sensitivity analysis resuits for transport of a $1 \mathrm{~kg}$ release of U-234 at the repository across a boundary $10 \mathrm{~m}$ from the release point: (9a) cumulative releases for individual sample elements, and (9b) PRCCs.

10. Distributions of CCDFs resulting from subjective uncertainty and obtained with replicate $\mathrm{R} 1$ for the following release modes: (10a) cuttings, (10b) spallings, (10c) direct brine release, and (10d) total (i.e., cuttings, spallings, direct brine).

11. Mean and percentile curves for distribution of total release CCDFs in Fig. 10d.

12. Outcome of replicated sampling for distribution of CCDFs for normalized release to the accessible environment over 10,000 yr due to direct brine release.

13. Scatterplots for expected (mean) normalized releases associated with individual CCDFs for direct brine release versus WRBRNSAT and HALPOR.

14. Sensitivity analysis based on PRCCs for CCDFs for total normalized release to the accessible environment over $10,000 \mathrm{yr}$. 


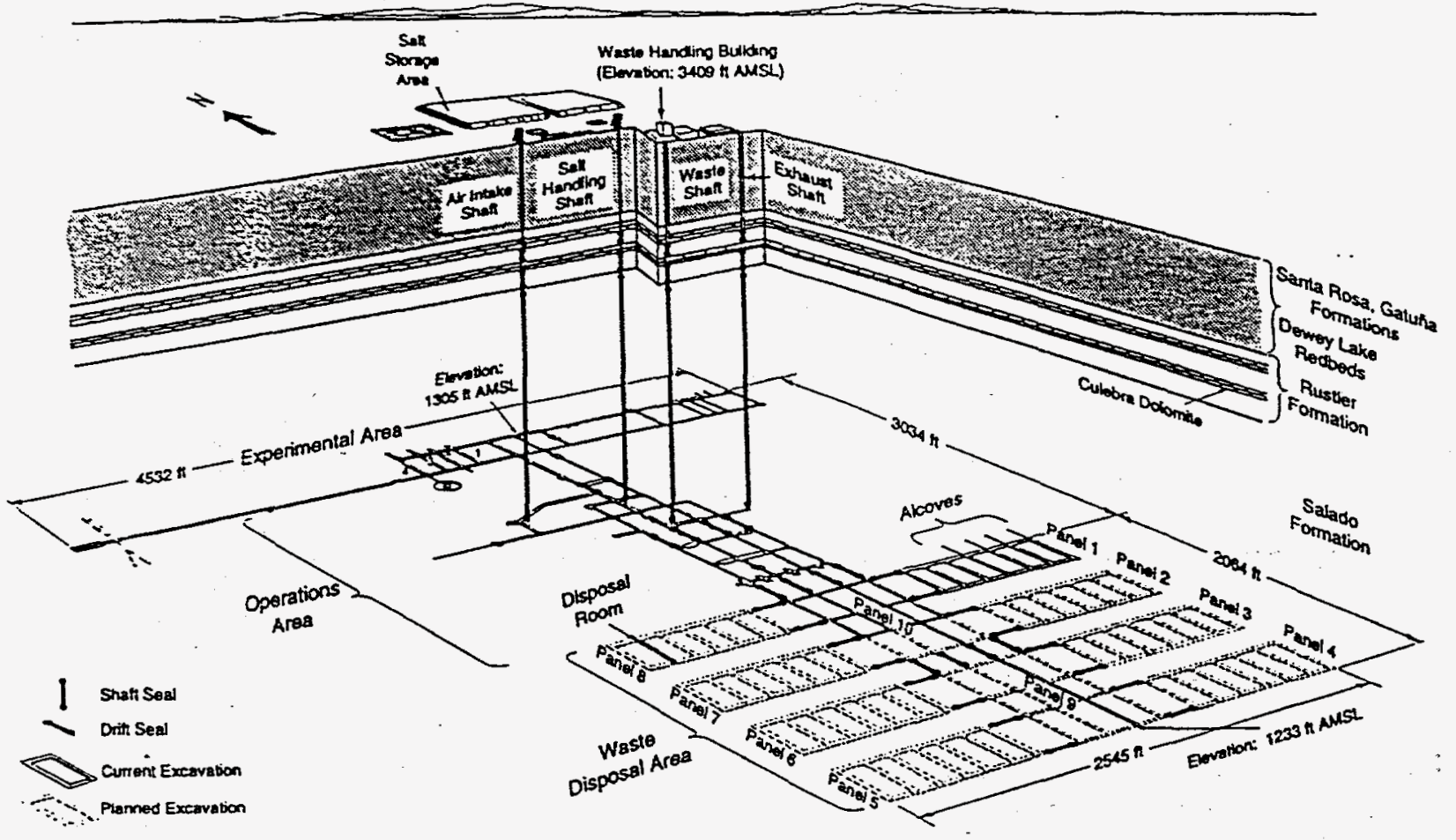

TFI- $6346-59-28$

Fig. 1. Cross-sectional view of the WIPP (Fig. 1-9, Vol. 1 [3]; see Sect. 2.2, Vol. 2 [4] for detailed stratigraphy).

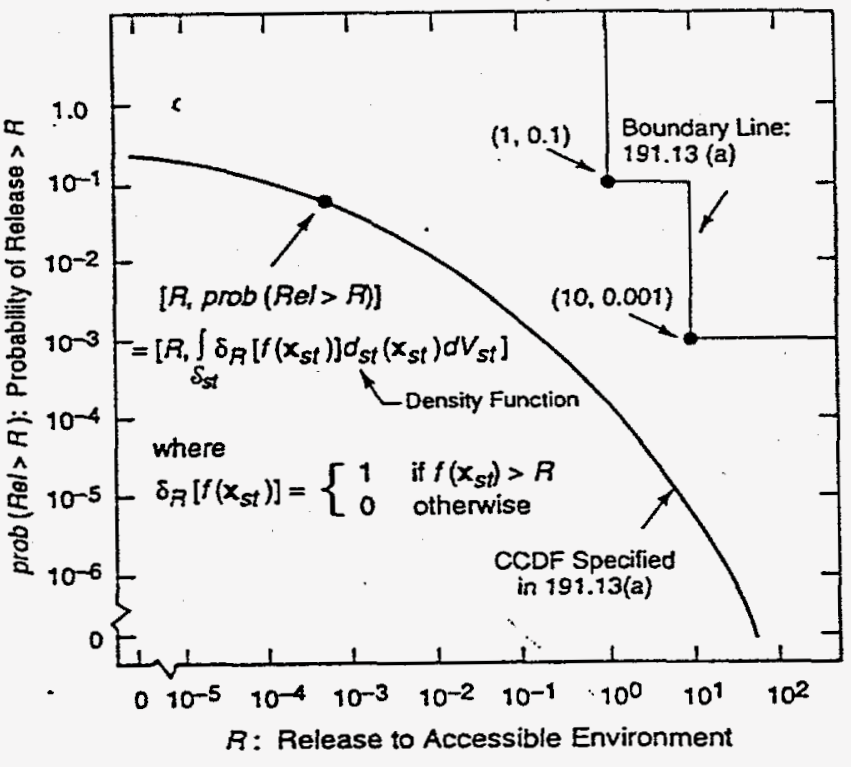

Fig. 2. Boundary line and associated CCDF specified in 191.13(a). 


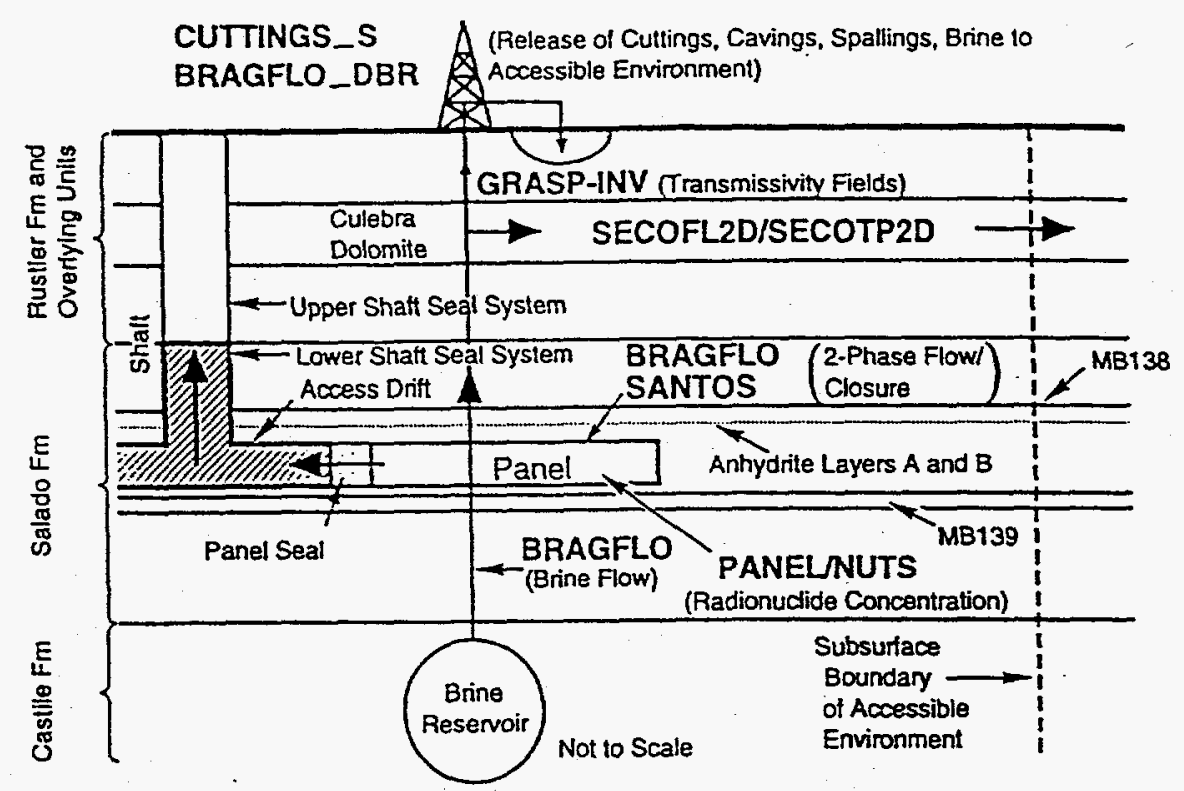

TRI-6342-3401-11

Fig. 3. Computer programs (models) used in 1996 WIPP PA.

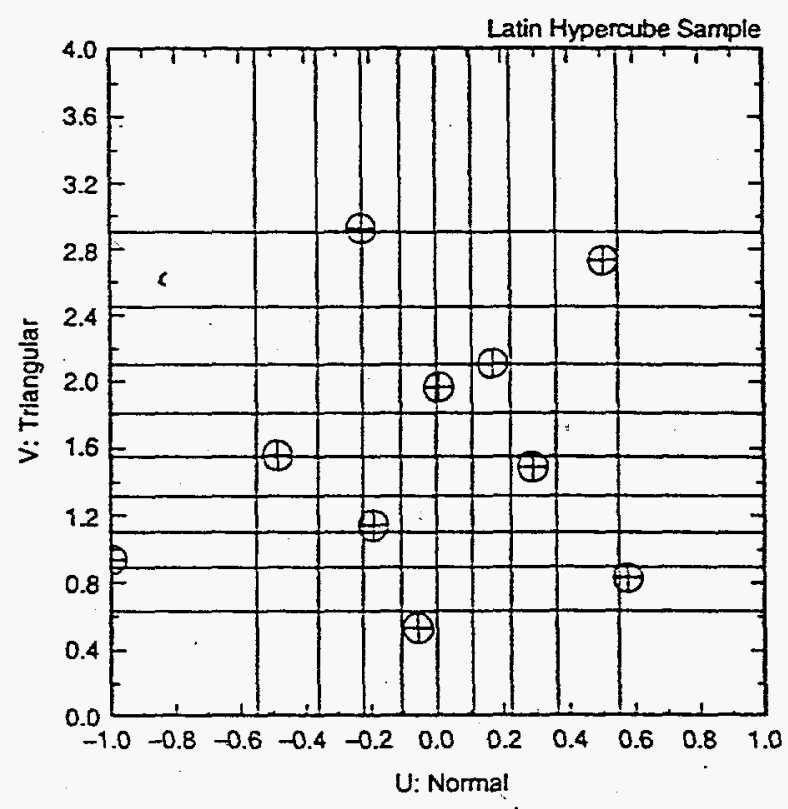

TRi-6342-5312-0

Fig. 4. Example of an LHS of size $n L H S=10$ from variables $U$ and $V$ with $U$ normal on $[-1,1]$ (mean $=0,0.01$ quantile $=-1,0.99$ quantile $=1)$ and $V$ triangular on $[0,4]$ (mode $=1)$. 

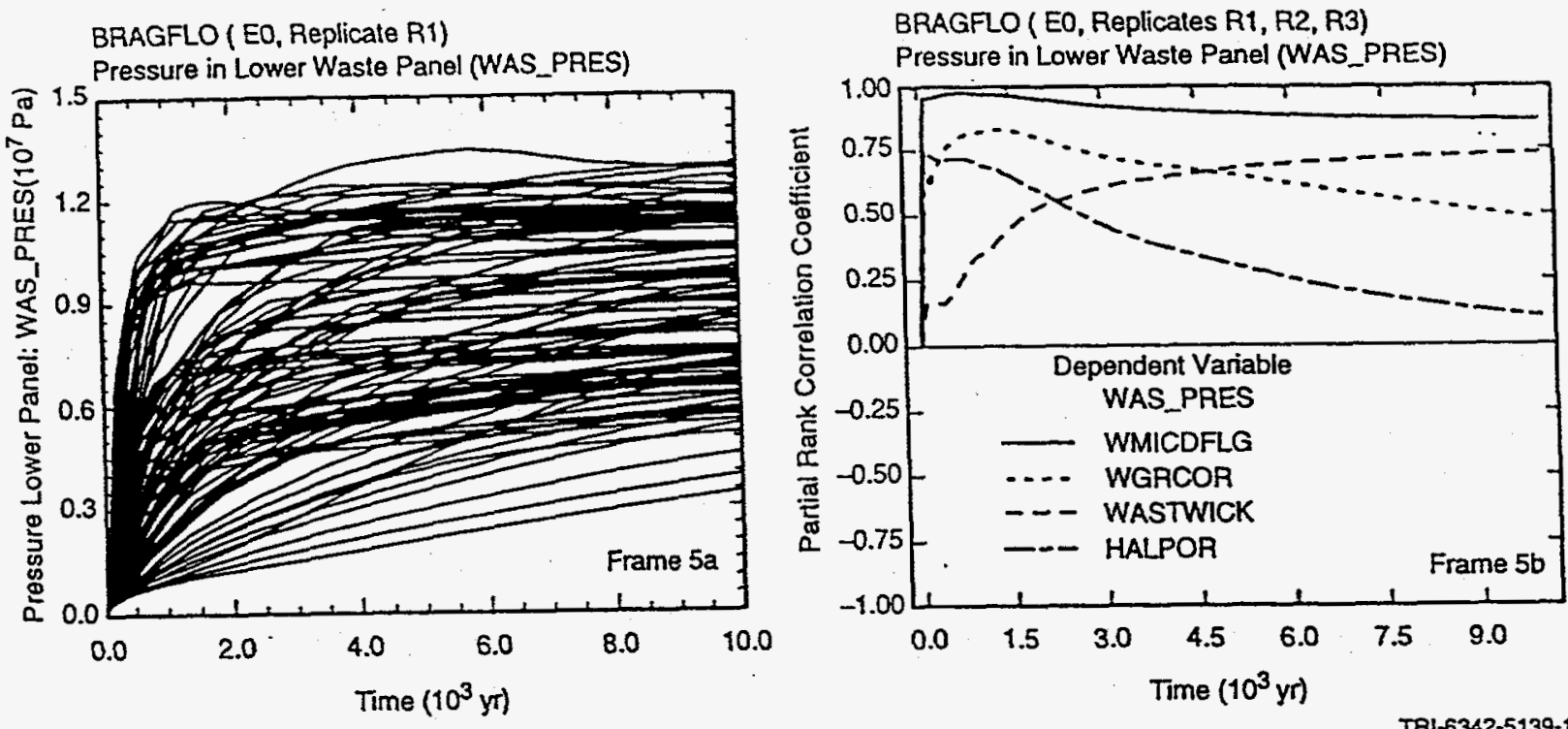

TRI-6342-5139-1

Fig. 5. Uncertainty and sensitivity analysis results for pressure $(\mathrm{Pa})$ in waste panel under undisturbed (i.e., E0) conditions: (5a) time-dependent pressures for 100 LHS elements in replicate R1, and (5b) PRCCs obtained from analysis of all 300 LHS elements associated with replicates R1, R2 and R3.

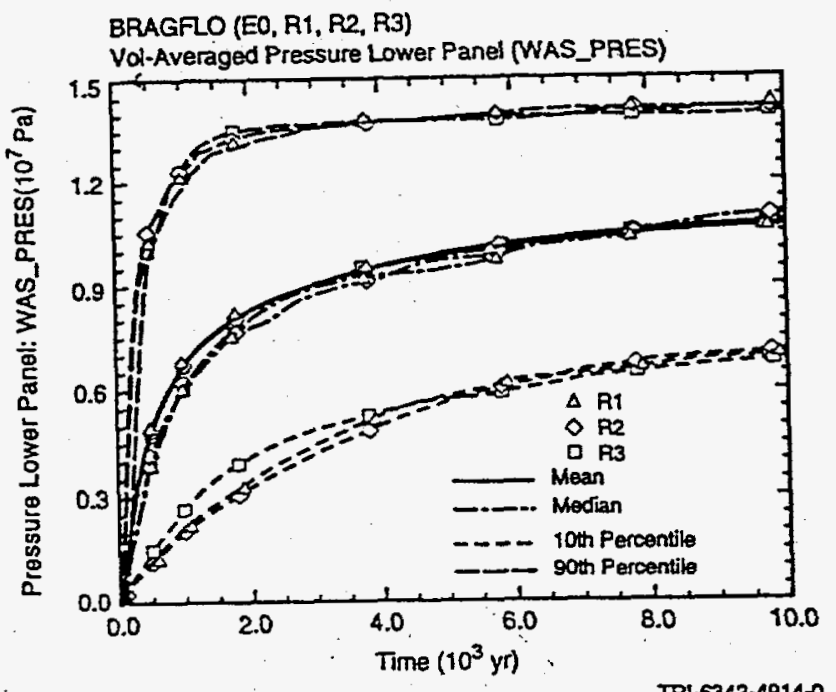

Fig. 6. Mean and percentile curves for three replicated LHSs for pressure in lower waste panel under undisturbed conditions. 

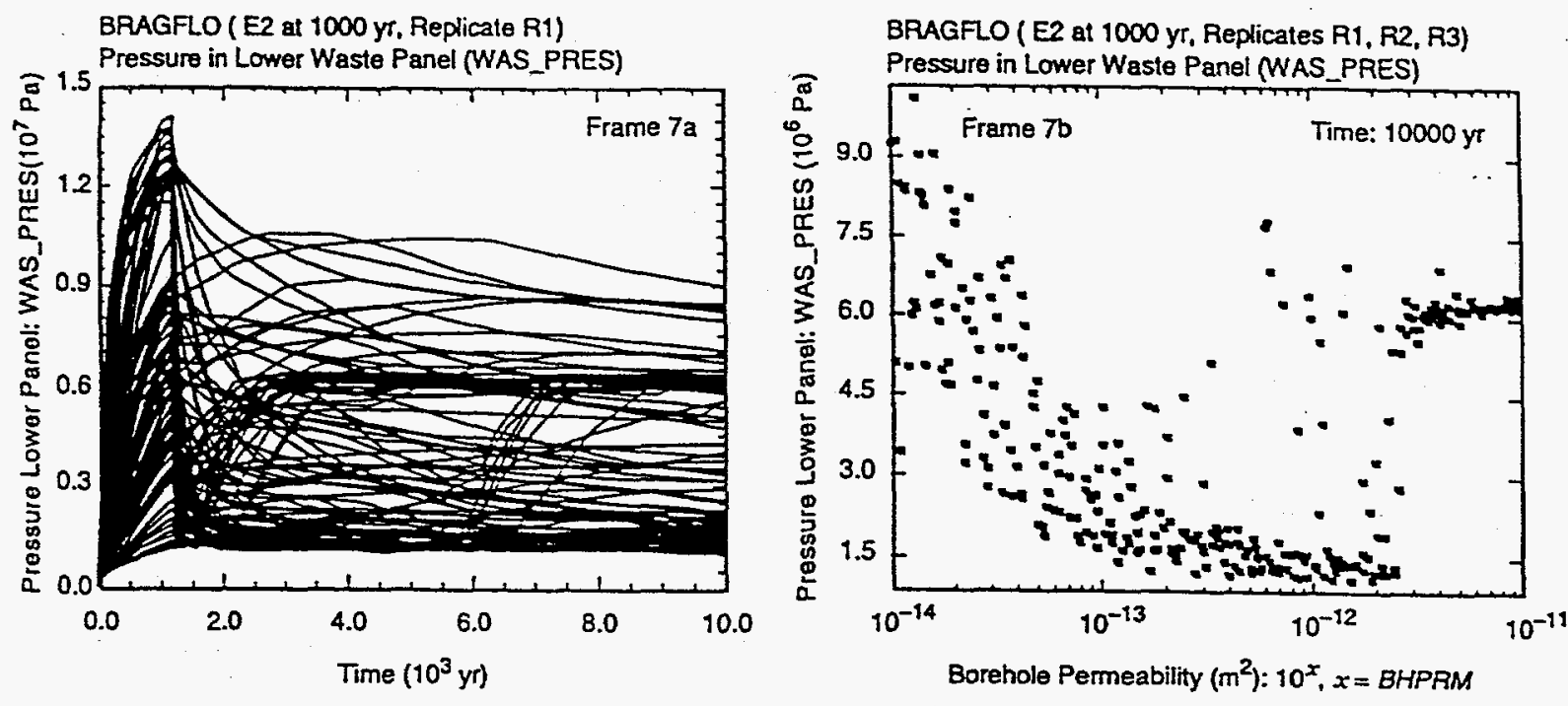

TRI-6342-5143-

Fig. 7. Uncertainty and sensitivity analysis results for pressure $(\mathrm{Pa})$ in waste panel after a drilling intrusion at $1000 \mathrm{yr}$ that does not penetrate pressurized brine in the Castile Formation (i.e., an E2 intrusion): (7a) time-dependent pressures for 100 LHS elements in replicate R1, and (7b) scatterplot for pressure at 10,000 yr versus $B H P R M$ for 300 LHS elements in replicates $R 1, R 2$ and $R 3$.

PANEL (E2E1 with E1 at $1000 \mathrm{yr}, \mathrm{R} 1, \mathrm{R} 2, \mathrm{R3}$ )

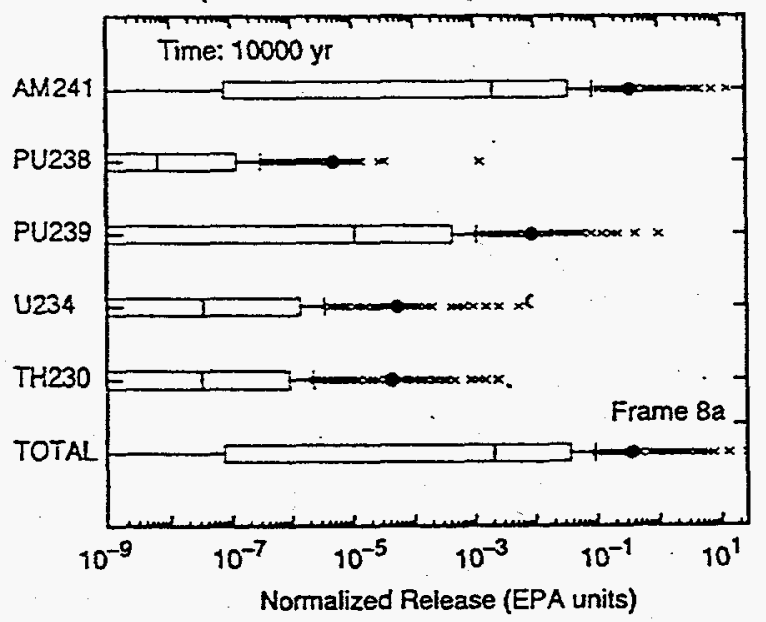

Min [1.5x Box, Largest Obs $]$

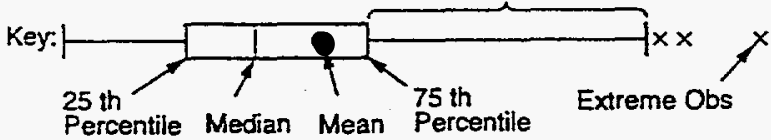

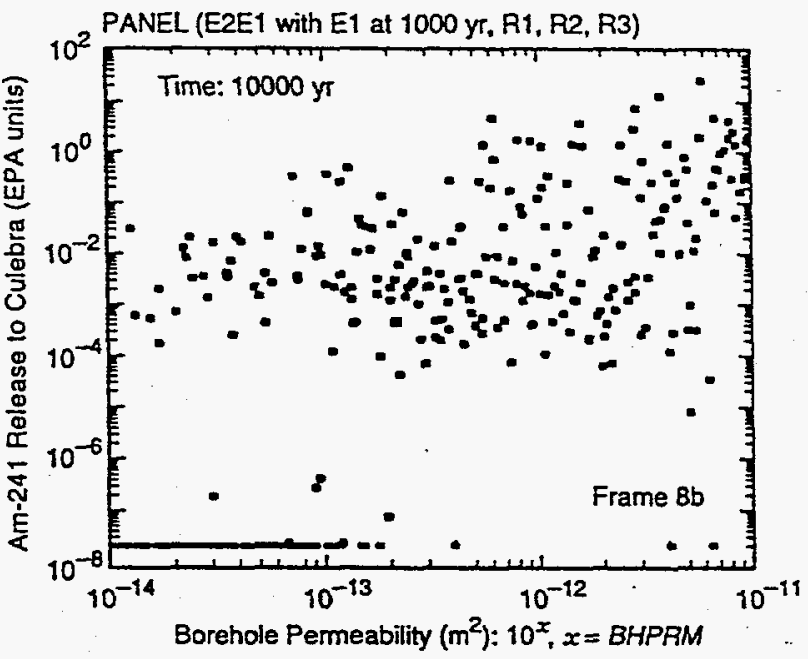

TRI-6342-5144-1

Fig. 8. Uncertainty and sensitivity analysis results for an E2E1 intrusion with the E1 intrusion occurring at 1000 yr: (8a) box plots for cumulative normalized release of individual radionuclides over $10,000 \mathrm{yr}$, and (8b) scatterplot for cumulative normalized release of Am-241 over 10,000 yr versus BHPRM. 

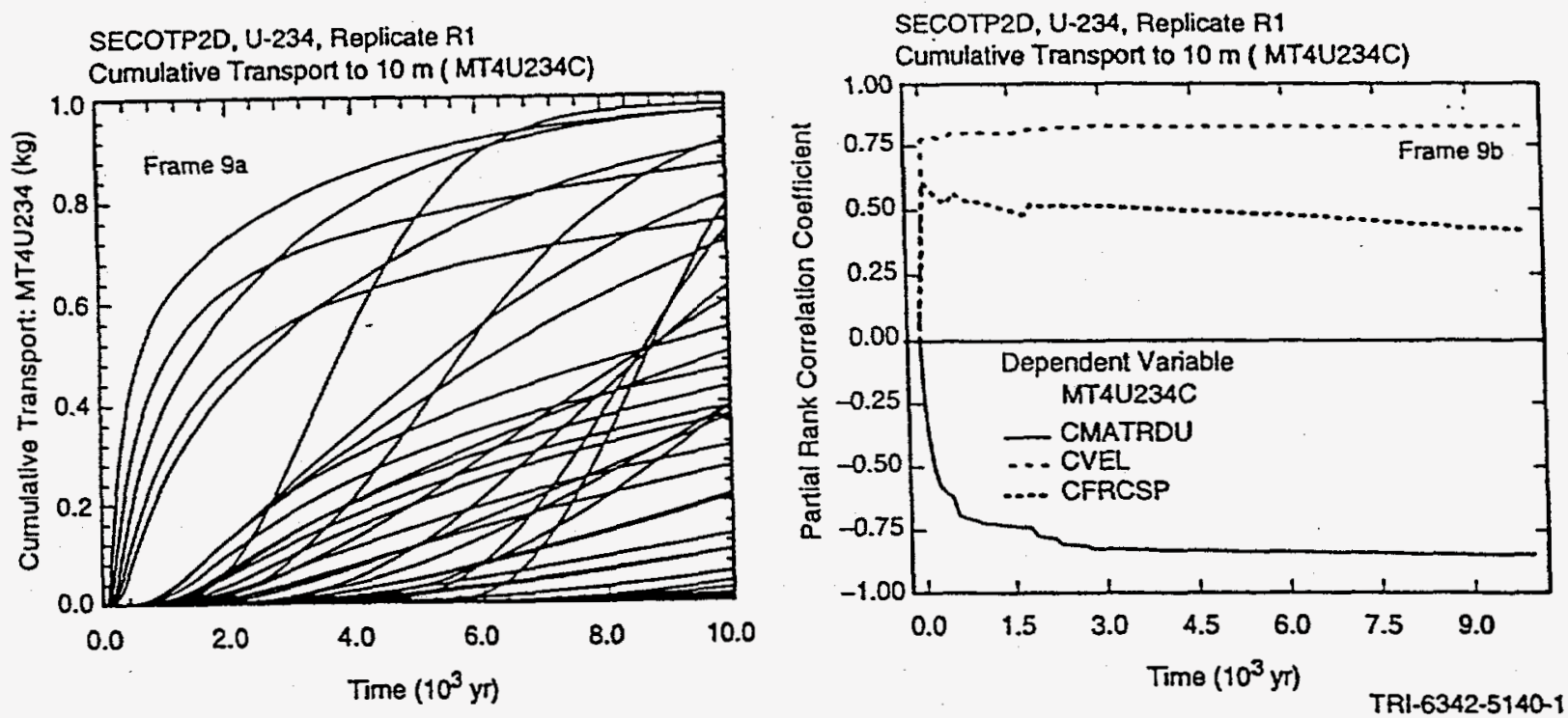

Fig. 9. Uncertainty and sensitivity analysis results for transport of a $1 \mathrm{~kg}$ release of U-234 at the repository across a boundary $10 \mathrm{~m}$ from the release point: (9a) cumulative releases for individual sample elements, and (9b) PRCCs. 

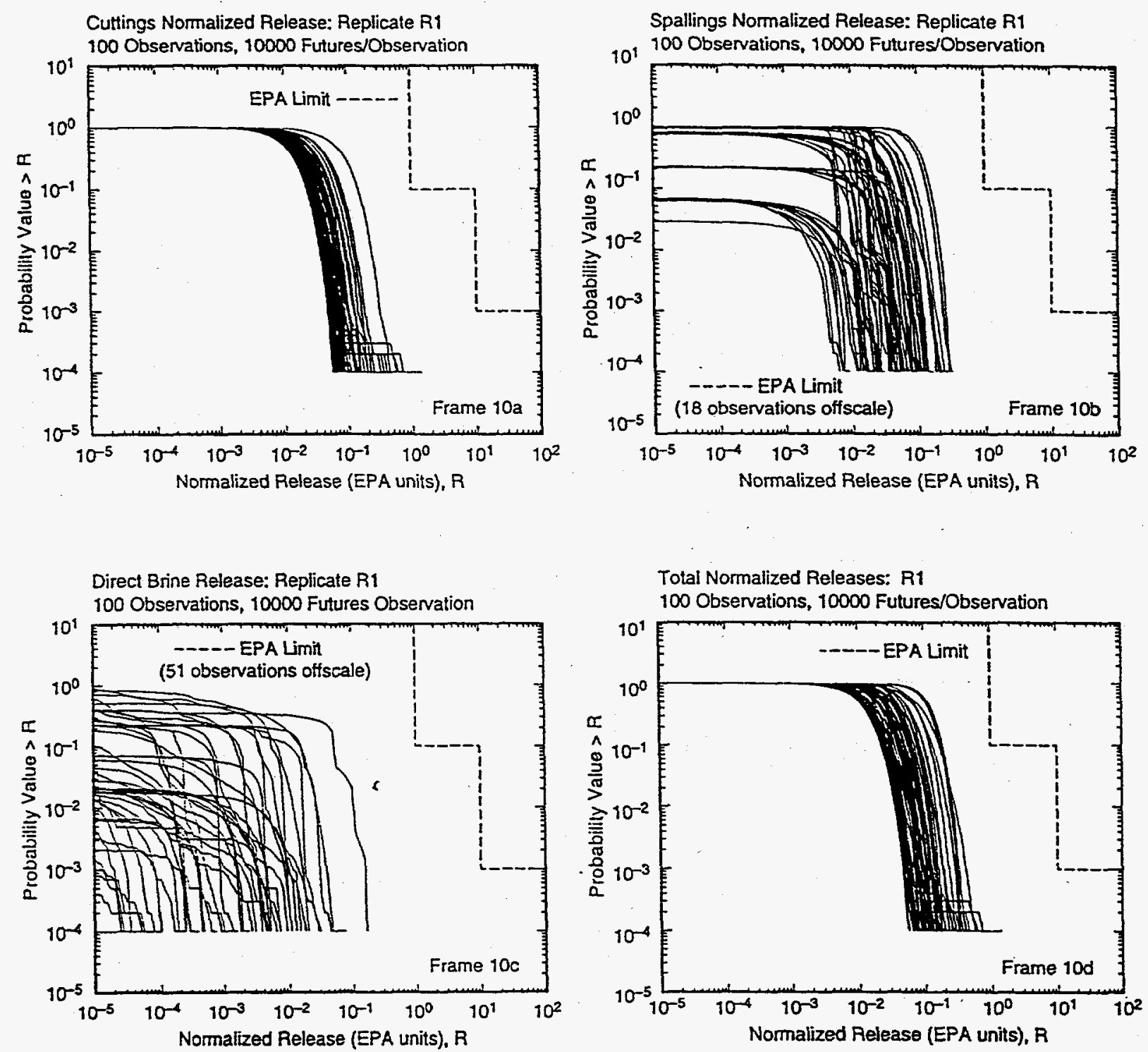

TA1-6342-5142-4

Fig. 10. Distributions of CCDFs resulting from subjective uncertainty and obtained with replicate $\mathrm{R} 1$ for the following release modes: $(10 \mathrm{a})$ cuttings, $(10 \mathrm{~b})$ spallings, $(10 \mathrm{c})$ direct brine release, and (10d) total (i.e., cuttings, spallings, direct brine). 


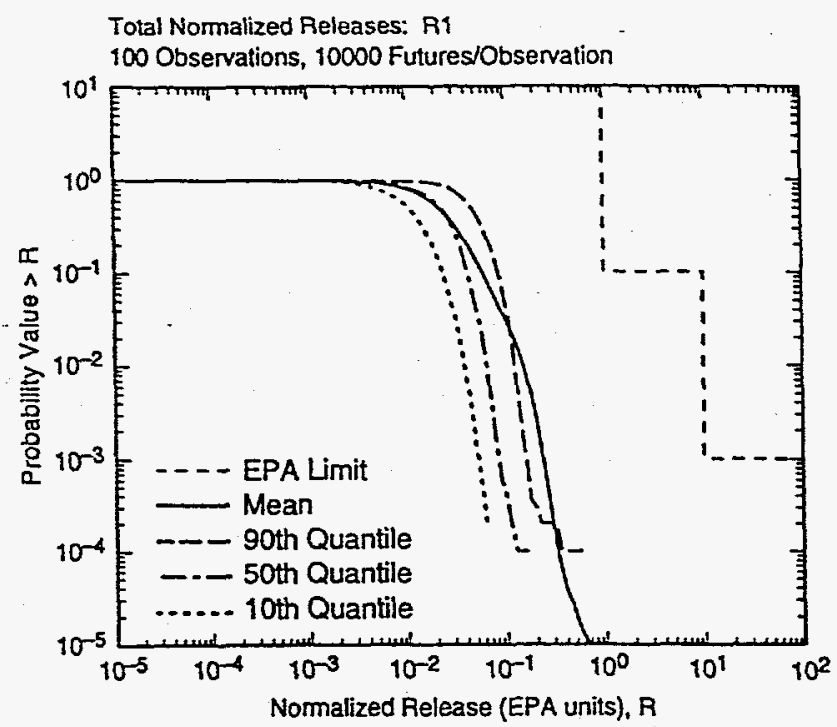

TPI-6342-5141-2

Fig. 11. Mean and percentile curves for distribution of total release CCDFs in Fig. 10d.

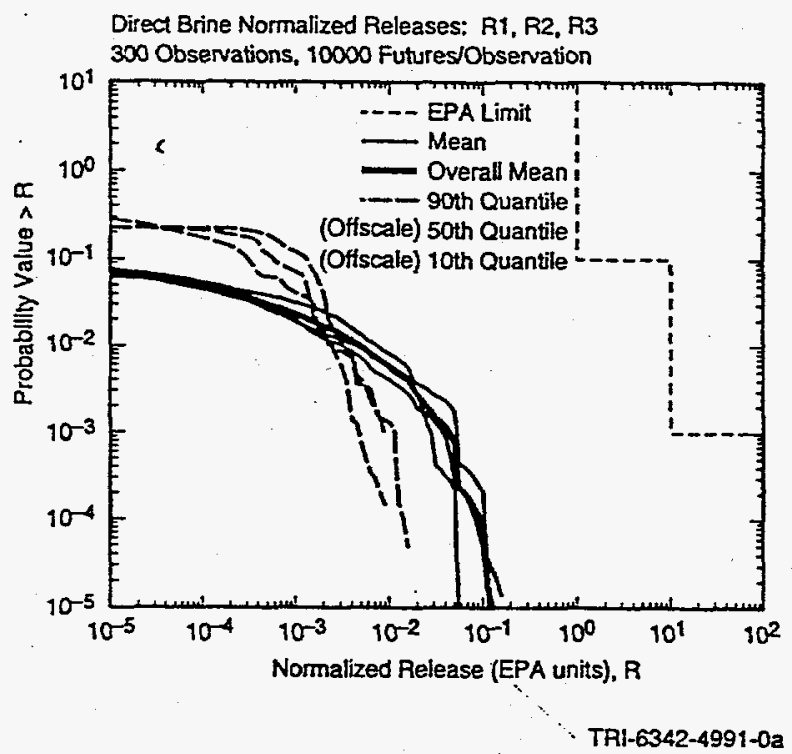

Fig. 12. Outcome of replicated sampling for distribution of CCDFs for normalized release to the accessible environment over $10,000 \mathrm{yr}$ due to direct brine release. 

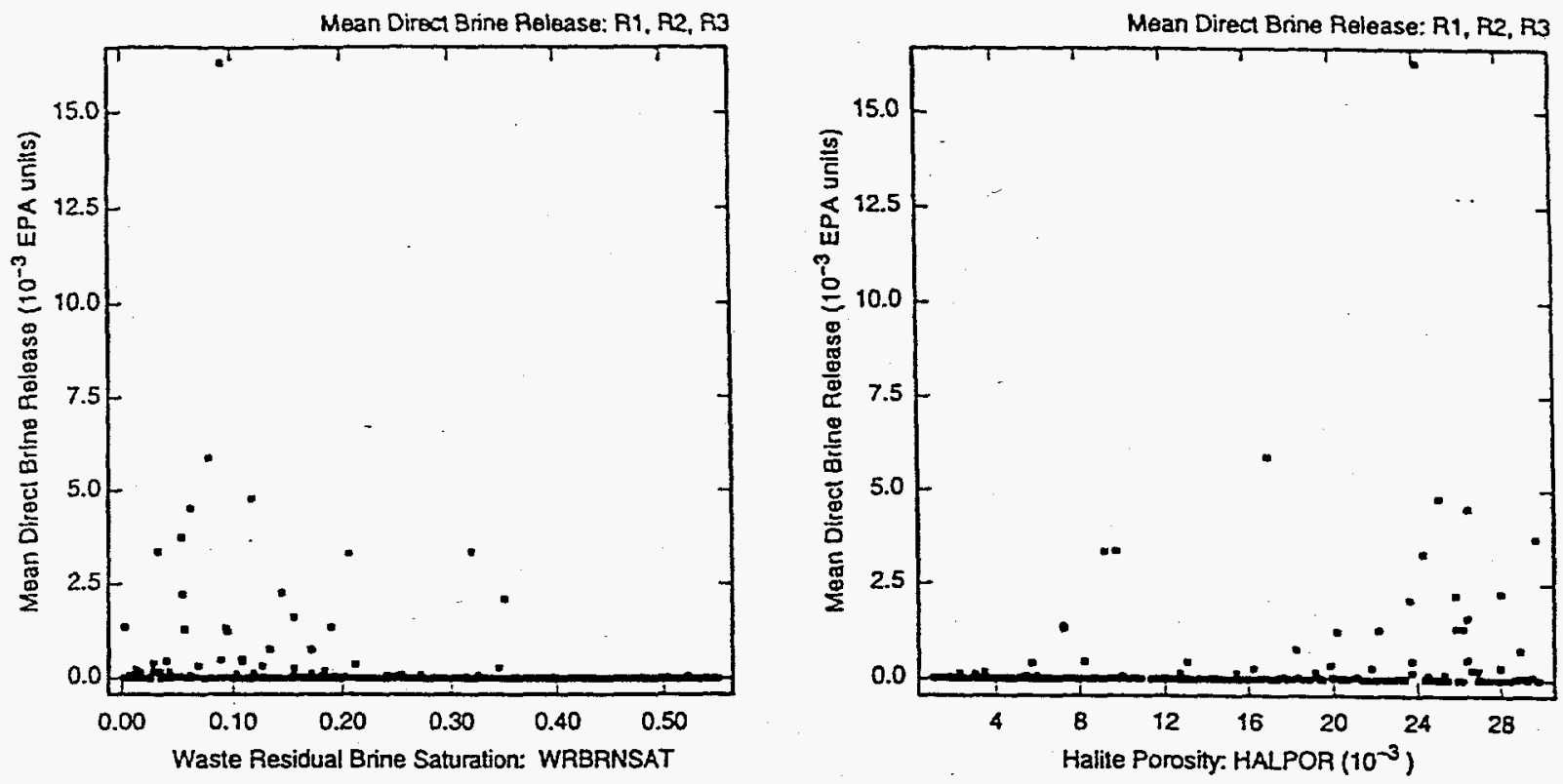

TR1-6342-5169-0

Fig. 13. Scatterplots for expected (mean) normalized releases associated with individual CCDFs for direct brine release versus WRBRNSAT and HALPOR.

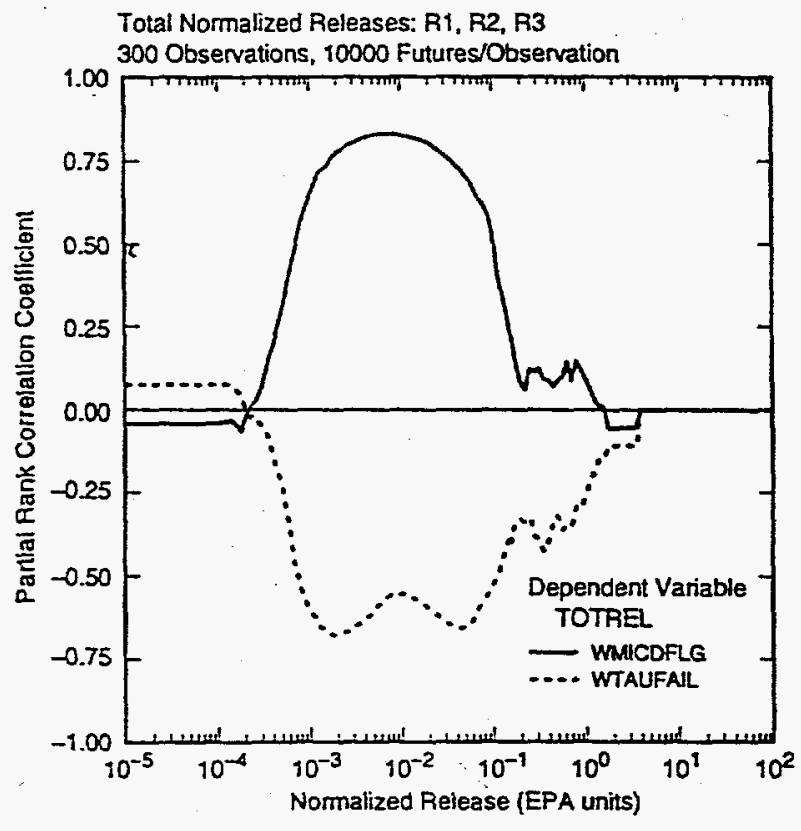

Fig. 14. Sensitivity analysis based on PRCCs for CCDFs for total normalized release to the accessible environment over $10,000 \mathrm{yr}$. 
Table 1. Summary of Computer Models Used in the 1996 WIPP PA

BRAGFLO: Calculates multiphase flow of gas and brine through a porous, heterogeneous reservoir. Uses finite difference procedures to solve system of nonlinear partial differential equations that describes the mass conservation of gas and brine along with appropriate constraint equations, initial conditions and boundary conditions. Additional information: [22]; Sect. 4.2, [13].

BRAGFLO_DBR: Special configuration of BRAGFLO model used in calculation of dissolved radionuclide releases to the surface (i.e., direct brine releases) at the time of a drilling intrusion. Uses initial value conditions obtained from calculations performed with BRAGFLO. Additional information: [23]; Sect. 4.7, [13].

CUTTINGS_S: Calculates the quantity of radioactive material brought to the surface in cuttings and cavings and also in spallings generated by an exploratory borehole that penetrates a waste panel, where cuttings designates material removed by the drillbit, cavings designates material eroded into the borehole due to shear stresses resulting from the circular flow of the drilling fluid (i.e., mud), and spallings designates material carried to the borehole at the time of an intrusion due to the flow of gas from the repository to the borehole. Spallings calculation uses initial value conditions obtained from calculations performed with BRAGFLO. Additional information: $[24,25]$; Sects. $4.5,4.6,[13]$.

GRASP-INV: Generates transmissivity fields (estimates of transmissivity values) conditioned on measured transmissivity values and calibrated to steady-state and transient pressure data at well locations using an adjoint sensitivity and pilot-point technique. Additional information: $[26,27]$.

NUTS: Solves system of partial differential equations for radionuclide transport in vicinity of repository. Uses brine volumes and flows calculated by BRAGFLO as input. Additional information: [28]; Sect. 4.3, [13].

PANEL: Calculates rate of discharge and cumulative discharge of radionuclides from a waste panel through an intruding borehole. Discharge is a function of fluid flow rate, elemental solubility and radionuclide inventory. Uses brine volumes and flows calculated by BRAGFLO as input. Based on solution of system of linear ordinary differential equations. Additional information: [28]; Sect. 4.4, [13].

SECOFL2D: Calculates single-phase Darcy flow for groundwater flow in two dimensions. The formulation is based on a single partial differential equation for hydraulic head using fully implicit time differencing. Uses transmissivity fields generated by GRASP-INV. Additional information: $[29,30]$; Sect. 4.8, [13].

SECOTP2D: Simulates transport of radionuclides in fractured porous media. Solves two partial differential equations: one provides two-dimensional representation for convective and diffusive radionuclide transport in fractures and the other provides one-dimensional representation for diffusion of radionuclides into rock matrix surrounding the fractures. Uses flow fields calculated by SECOFL2D. Additional information: $[29,30]$; Sect. 4.9, [13].

SANTOS: Solves quasistatic, large deformation, inelastic response of two-dimensional solids with finite element techniques. Used to determine porosity of waste as a function of time and cumulative gas generation, which is an input to calculations performed with BRAGFLO. Additional information: [22, 31, 32]; in Sect. 4.2.3, [13]. 
Table 2. Example Elements of $\mathbf{x}_{s u}$ in the 1996 WIPP PA (sce Table 5.1 [13] for a complete listing of the $n V=57$ elements of $x_{s u}$ and sources of additional information)

ANHPRM-Logarithm of anhydrite permeability $\left(\mathrm{m}^{2}\right)$. Used in BRAGFLO. Distribution: Student's t-distribution with 5 degrees of freedom. Range: -21.0 to -17.1 (i.e., permeability range is $1 \times 10^{-21}$ to $1 \times 10^{-17.1} \mathrm{~m}^{2}$ ). Mean, Median: $-18.9,-18.9$. Correlation : -0.99 rank correlation with ANHCOMP (Bulk compressibility of anhydrite, $\mathrm{Pa}^{-1}$ ).

BHPRM - Logarithm of borehole permeability $\left(\mathrm{m}^{2}\right)$. Used in BRAGFLO. Distribution: Uniform. Range: -14 to -11 (i.e., permeability range is $1 \times 10^{-14}$ to $1 \times 10^{-11} \mathrm{~m}^{2}$ ). Mean, median: $-12.5,-12.5$.

BPCOMP-Logarithm of bulk compressibility of brine pocket $\left(\mathrm{Pa}^{-1}\right)$. Used in BRAGFLO. Distribution: Triangular. Range: -11.3 to -8.00 (i.e., bulk compressibility range is $1 \times 10^{-11.3}$ to $1 \times 10^{-8} \mathrm{~Pa}^{-1}$ ). Mean, mode: -9.80, -10.0. Correlation: -0.75 rank correlation with BPPRM (Logarithm of brine pocket permeability, $\mathrm{m}^{2}$ ).

BPINTPRS-Initial pressure in brine pocket $(\mathrm{Pa})$. Used in BRAGFLO. Distribution: Triangular. Range: $1.11 \times$ $10^{7}$ to $1.70 \times 10^{7} \mathrm{~Pa}$. Mean, mode: $1.36 \times 10^{7} \mathrm{~Pa}, 1.27 \times 10^{7} \mathrm{~Pa}$.

CFRCSP - Culebra fracture spacing (m). Used in SECOTP2D. Equal to half the distance between fractures. Distribution: Uniform. Range: 0.05 to $0.5 \mathrm{~m}$. Mean, median: $0.275 \mathrm{~m}, 0.275 \mathrm{~m}$.

CMATRDU-Culebra matrix retardation for uranium (dimensionless). Defined as function of other uncertain variables. Used in SECOTP2D. Not a sampled variable.

CVEL - Norm of Culebra fluid velocity vector calculated by SECOFL2D $(\mathrm{m} / \mathrm{s})$. Defined as function of other uncertain variables. Representative of fluid velocity used in SECOTP2D. Not a sampled variable.

HALPOR - nnitial value for halite porosity (dimensionless). Used in BRAGFLO. Distribution: Piecewise uniform. Range: $1.0 \times 10^{-3}$ to $3 \times 10^{-2}$. Mean, median: $1.28 \times 10^{-2}, 1.00 \times 10^{-2}$.

HALPRM-Logarithm of halite permeability $\left(\mathrm{m}^{2}\right)$. Used in BRAGFLO. Distribution: Uniform. Range: -24 to -21 (i.e., permeability range is $1 \times 10^{-24}$ to $1 \times 10^{-21} \mathrm{~m}^{2}$ ). Mean, median: $-22.5,-22.5$. Correlation: -0.99 rank correlation with HALCOMP (Bulk compressibility of halite, $\mathrm{Pa}^{-1}$ ).

WASTWICK - Increase in brine saturation of waste due to capillary forces (dimensionless). Used in BRAGFLO. Distribution: Uniform. Range: 0 to 1 . Mean, median: $0.5,0.5$.

WGRCOR-Corrosion rate for steel under inundated conditions in the absence of $\mathrm{CO}_{2}(\mathrm{~m} / \mathrm{s})$. Used in BRAGFLO. Distribution: Uniform. Range: 0 to $1.58 \times 10^{-14} \mathrm{~m} / \mathrm{s}$. Mean, median: $7.94 \times 10^{-15} \mathrm{~m} / \mathrm{s}, 7.94 \times$ $10^{-15} \mathrm{~m} / \mathrm{s}$.

WMICDFLG_Pointer variable for microbial degradation of cellulose. Used in BRAGFLO. Distribution: Discrete, with $50 \% 0,25 \% 1,25 \% 2$. WMICDFLG $=0,1,2$ implies no microbial degradation of cellulose, microbial degradation of only cellulose, microbial degradation of cellulose, plastic and rubber.

WPRTDIAM -Waste particle diameter (m). Used in CUTTINGS_S. Distribution: Loguniform. Range: $4.0 \times$ $10^{-5}$ to $2.0 \times 10^{-1} \mathrm{~m}$. Mean, median: $2.35 \times 10^{-2} \mathrm{~m}, 2.80 \times 10^{-2} \mathrm{~m}$.

WRBRNSAT - Residual brine saturation in waste (dimensionless). Used in BRAGFLO and BRAGFLO_DBR. Distribution: Uniform. Range: 0 to 0.552 . Mean, median: $0.276,0.276$.

WTAUFAIL - Shear strength of waste $(\mathrm{Pa})$. Used in CUTTINGS_S. Distribution: Uniform. Range: 0.05 to 10 $\mathrm{Pa}$. Mean, median: $5.03 \mathrm{~Pa}, 5.03 \mathrm{~Pa}$. 
Table 3. Mechanistic Calculations Performed as Part of the Uncertainty and Sensitivity Analyses in the 1996 WIPP PA

\section{BRAGFLO}

Individual Calculations (6 cases): E0 (i.e., undisturbed conditions); E1 at 350, $1000 \mathrm{yr}$ (i.e., drilling intrusion through repository that penetrates pressurized brine in the Castile Fm); E2 at 350, 1000 yr (i.e., drilling intrusion through repository that does not penetrate pressurized brine in the Castile Fm); E2E1 with E2 intrusion at 800 yr and E1 intrusion at $1000 \mathrm{yr}$. Total calculations: $6 n R n L H S=6 \cdot 3 \cdot 100=1800$.

\section{CUTTINGS_S}

Individual Calculations (52 cases): Intrusion into lower waste panel in previously unintruded (i.e., E0 conditions) repository at $100,350,1000,3000,5000,10,000 \mathrm{yr}$; Intrusion into upper waste panel in previously unintruded repository at $100,350,1000,3000,5000,10,000 \mathrm{yr}$; Initial $\mathrm{El}$ intrusion at $350 \mathrm{yr}$ followed by a second intrusion into the same waste panel at $550,750,2000,4000$ or $10,000 \mathrm{yr}$; Initial E1 intrusion at $350 \mathrm{yr}$ followed by a second intrusion into a different waste panel at $550,750,2000,4000$ or $10,000 \mathrm{yr}$; Initial E1 intrusion at $1000 \mathrm{yr}$ followed by a second intrusion into the same waste panel at $1200,1400,3000,5000$ or 10,000 yr; Initial El intrusion at $1000 \mathrm{yt}$ followed by a second intrusion into a different waste panel at 1200,1400,3000,5000 or $10,000 \mathrm{yr}$; same 23 cases for initial E2 intrusions as for initial E1 intrusions. Total calculations: $52 n R n L H S=$ $52 \cdot 3 \cdot 100=15,600$.

\section{BRAGFLO_DBR}

Same computational cases as for CUTTINGS_S

\section{NUTS}

Individual Calculations (15 cases): E0; $\mathrm{E} 1$ at 100, 350, 1000, 3000, 5000, 7000, $9000 \mathrm{yr} ; \mathrm{E} 2$ at 100, 350, 1000, $3000,5000,7000,9000$ yr. Screening calculations: $5 n R$ nLHS $=1500$. Total NUTS calculations: 594. Note: Screening calculations were initially performed for each LHS element (i.e., E0, E1 at 350 and 1000 yr, E2 at 350 and $1000 \mathrm{yr}$, which produces the multiplier of 5 in the calculation of the number of screening calculations) to determine if the potential for a radionuclide release existed, with a full NUTS calculation only being performed when such a potential existed.

\section{PANEL}

Individual Calculations ( 7 cases): E2E1 at 100, 350, 1000, 2000, 4000, 6000, 9000 yr. Total calculations: $7 n R$ $n L H S=7 \cdot 3 \cdot 100=2100$. Note: Additional PANEL calculations were also performed at 100, 125, 175, 350, $1000,3000,5000,7500$ and 10,000 Yyr for Salado-dominated brines and also for Castile-dominated brines to determine dissolved radionuclide concentrations for use in the determination of direct brine releases.

\section{SECOFL2D .}

Individual Calculations ( 2 cases): Partially mined conditions in vicinity of repository; Fully mined conditions in vicinity of repository. Total calculations: $2 n R n L H S=2 \bullet 3 \bullet 100=600$.

\section{SECOTP2D}

Individual Calculations (2 cases): Partially mined conditions in vicinity of repository; Fully mined conditions in vicinity of repository. Total calculations: $2 n R n L H S=2 \bullet 3 \bullet 100=600$. Note: Each calculation is for four radionuclides: Am-241, Pu-239, Th-230, U-234. Further, calculations are done for unit releases at time $0 \mathrm{yr}$, which can then be used to construct transport results for the Culebra for arbitrary time-dependent release rates into the Culebra (Sect. 12.2, [13]). 
Table 4. Stepwise Regression Analysis with Rank-Transformed Data for Expected Normalized Release Associated with Individual CCDFs for Spallings Release, Direct Brine Release, and Total Releasc.

\begin{tabular}{|c|l|r|r|l|l|l|l|l|r|c|}
\cline { 2 - 9 } \multicolumn{4}{c|}{ Spallings Release } & \multicolumn{3}{c|}{ Direct Brine Release. } & \multicolumn{3}{c|}{ Total Release } \\
\hline Step $^{\mathrm{a}}$ & Variable & SRRC $^{\mathrm{b}}$ & $R^{2 \mathrm{~d}}$ & Variable & SRRC & $R^{2}$ & Variable & SRRC & $R^{2}$ \\
\hline 1 & WMICDFLG & 0.72 & 0.53 & WRBRNSAT & -0.46 & 0.21 & WMICDFLG & 0.60 & 0.40 \\
2 & HALPOR & 0.26 & 0.60 & HALPOR & 0.37 & 0.35 & WTAUFAIL & -0.39 & 0.55 \\
3 & WGRCOR & 0.24 & 0.66 & ANHPRM & 0.27 & 0.42 & WGRCOR & 0.21 & 0.59 \\
4 & BHPRM & -0.20 & 0.70 & BPCOMP & 0.20 & 0.46 & WPRTDIAM & -0.19 & 0.63 \\
5 & WPRTDIAM & -0.19 & 0.73 & BPINTPRS & 0.14 & 0.48 & HALPOR & 0.17 & 0.65 \\
6 & HALPRM & 0.13 & 0.75 & HALPRM & 0.14 & 0.50 & BHPRM & -0.17 & 0.68 \\
7 & WASTWICK & 0.11 & 0.76 & & & & HALPRM & 0.16 & 0.71 \\
8 & ANHPRM & 0.10 & 0.77 & & & & WASTWICK & 0.11 & 0.72 \\
9 & & & & & & & & & & \\
\hline
\end{tabular}

a Steps in stepwise regression analysis.

b Variables listed in order of selection in regression analysis.

c Standardized regression coefficients in final regression model with ANHCOMP and HALCOMP excluded from entry into regression model because of the -0.99 rank correlation within the variable pairs (ANHPRM, ANHCOMP) and (HALPRM, HALCOMP).

d Cumulative $R^{2}$ value with entry of each variable into regression model. 